\title{
Enhancement of Second-Order Optical Nonlinearity in a Lutetium Sele- nite by Monodentate Anion Partial Substitution
}

\author{
Chao Wu,${ }^{\dagger}$ Longhua Li,${ }^{\dagger}$ Lin Lin,${ }^{\dagger}$ Zhipeng Huang, ${ }^{\dagger}$ Mark G. Humphrey, ${ }^{\ddagger}$ and Chi Zhang*, ${ }^{\dagger}$ \\ ${ }^{\dagger}$ China-Australia Joint Research Center for Functional Molecular Materials, School of Chemical Science and Engineering, \\ Tongji University, Shanghai 200092, China \\ * Research School of Chemistry, Australian National University, Canberra, ACT 2601, Australia
}

\begin{abstract}
The systematic modification of the molecular structure of nonlinear optical (NLO)-active materials is a very attractive approach to the improvement of NLO performance. In this study, one lutetium selenite compound $\mathrm{Lu}\left(\mathrm{SeO}_{3}\right)\left(\mathrm{HSeO}_{3}\right)\left(\mathrm{H}_{2} \mathrm{O}\right) \cdot\left(\mathrm{H}_{2} \mathrm{O}\right)(\mathbf{1})$ was synthesized by hydrothermal means, while a further two lutetium selenites $\mathrm{Lu}_{3} \mathrm{~F}\left(\mathrm{SeO}_{3}\right)_{4}(\mathbf{2})$ and $\mathrm{Lu}\left(\mathrm{SeO}_{3}\right)\left(\mathrm{NO}_{3}\right)\left(\mathrm{H}_{2} \mathrm{O}\right)(3)$ were successfully synthesized by anion partial substitution (APS) of the parent structure 1 under hydrothermal conditions. Specifically, substitution of the $\left[\mathrm{HSeO}_{3}\right]^{-}$anions in the noncentrosymmetric 1 by $\mathrm{F}^{-}$or $\left[\mathrm{NO}_{3}\right]^{-}$anions with differing denticity leads to the formation of polar $\mathbf{2}$ and centrosymmetric $\mathbf{3}$. Our study reveals that the denticity of the secondary functional anions has a significant influence on the coordination environments of the rare-earth metal cation $\mathrm{Lu}^{3+}$ and consequently the molecular configuration and NLO performance of the resultant multidimensional selenites. In contrast to 1, which displays a weak second-harmonic generation (SHG) response $\left(0.1 \times \mathrm{KH}_{2} \mathrm{PO}_{4}(\mathrm{KDP})\right), 2$ exhibits a greatly improved NLO performance, including a strong SHG signal $(2.5 \times \mathrm{KDP}$, the highest value among rare-earth-metal-based NLO selenites), a wide band gap (3.57 $\mathrm{eV})$ and optical transparency window $(0.35-10.3 \mu \mathrm{m})$, high thermal stability $\left(\sim 550{ }^{\circ} \mathrm{C}\right)$, and a large laser damage threshold $(36 \times$ $\mathrm{AgGaS}_{2}$ ). These results suggest that $\mathbf{2}$, as the first example of a fluorinated lutetium selenite, is a strong NLO candidate crystal spanning a region from the near-ultraviolet to the mid-infrared. These APS studies highlight a new feasible approach towards highperformance NLO crystals.
\end{abstract}

\section{INTRODUCTION}

Nonlinear optical (NLO) crystalline materials with secondharmonic generation (SHG) properties play a crucial role in laser-based technologies because their frequency conversion ability can extend the output spectral ranges of laser sources. ${ }^{1-8}$ Over the past decades, a series of state-of-the-art NLO crystals have been discovered, including $\mathrm{KBe}_{2} \mathrm{~B}_{2} \mathrm{O}_{6} \mathrm{~F}_{2}(\mathrm{KBBF}){ }^{9}{ }^{9} \beta$ $\mathrm{BaB}_{2} \mathrm{O}_{4}(\mathrm{BBO}){ }^{10}{ }^{2} \mathrm{LiB}_{3} \mathrm{O}_{5}(\mathrm{LBO}),{ }^{11} \mathrm{KH}_{2} \mathrm{PO}_{4}(\mathrm{KDP}),{ }^{12} \mathrm{KTi}-$ $\mathrm{OPO}_{4}(\mathrm{KTP}){ }_{13}^{13}$ and $\mathrm{AgGaS}_{2} \cdot{ }^{14}$ These materials, however, are unable to fully satisfy all requirements imposed by the various application wavelengths. New high-performance NLO materials are consequently of enormous current academic and commercial interest. ${ }^{1-8,15-22}$

Inorganic metal selenites form an important category of NLO candidates. ${ }^{23-36}$ The lone pair electrons on $\left[\mathrm{SeO}_{3}\right]^{2-}$ anions favor the formation of noncentrosymmetric (NCS) materials with excellent SHG properties. ${ }^{37}$ Many efforts have been focused on the introduction of $\mathrm{d}^{0}$ transition metal (TM) into metal selenite systems. ${ }^{23-29}$ Examples include $\mathrm{A}_{2}\left(\mathrm{MoO}_{3}\right)_{3}\left(\mathrm{SeO}_{3}\right)(\mathrm{A}=\mathrm{Rb}, \mathrm{Tl}),{ }^{23} \mathrm{Cs}(\mathrm{TiOF})_{3}\left(\mathrm{SeO}_{3}\right)_{2},{ }^{24} \mathrm{TlSe}-$ $\mathrm{VO}_{5},{ }^{25} \mathrm{ASe}_{2} \mathrm{~V}_{3} \mathrm{O}_{12}(\mathrm{~A}=\mathrm{Rb}, \mathrm{Tl}),{ }^{26} \mathrm{NaNbO}\left(\mathrm{SeO}_{3}\right)_{2},{ }^{27}$ and $\mathrm{Na}_{2}\left(\mathrm{WO}_{3}\right)_{3}\left(\mathrm{SeO}_{3}\right) \cdot 2 \mathrm{H}_{2} \mathrm{O} .{ }^{28}$ Recently, incorporating main-group cations $\left(\right.$ e.g. $\mathrm{Bi}^{3+}$ and $\left.\mathrm{Pb}^{2+}\right)$ with lone pair electrons into the selenite can furnish NCS materials with enhanced SHG responses, ${ }^{30-36}$ such as $\mathrm{BiFSeO}_{3}{ }^{30}$ and $\mathrm{Pb}_{2} \mathrm{GaF}_{2}\left(\mathrm{SeO}_{3}\right)_{2} \mathrm{Cl}^{31}$ Trivalent rare-earth metal cations $\left(\right.$ e.g. $\mathrm{Sc}^{3+}, \mathrm{Y}^{3+}, \mathrm{La}^{3+}, \mathrm{Gd}^{3+}$, and $\mathrm{Lu}^{3+}$ ) without $\mathrm{d}-\mathrm{d}$ or $\mathrm{f}-\mathrm{f}$ electronic transitions have also been pursued as NLO materials that often possess wide optical transparency windows. ${ }^{38,39}$ However, all extant rare-earthmetal-based NLO selenites suffer from centrosymmetric (CS) structures or weak SHG responses, ${ }^{40-42}$ in contrast to some other lone pair cation-containing selenites. ${ }^{30-36}$

Herein, we report the first example of a NCS lutetium selenite crystal, $\mathrm{Lu}\left(\mathrm{SeO}_{3}\right)\left(\mathrm{HSeO}_{3}\right)\left(\mathrm{H}_{2} \mathrm{O}\right) \cdot\left(\mathrm{H}_{2} \mathrm{O}\right)(\mathbf{1})$, prepared via a hydrothermal synthesis, together with its crystal structure and NLO properties. Unfortunately, the lone pairs on the selenite groups $\left[\mathrm{SeO}_{3}\right]^{2-}$ of $\mathbf{1}$ orient in an antiparallel fashion, resulting in dipole moment elimination and thereby a very weak SHG response. Considering the affinity of rare-earth metal cations for diverse functional anions, ${ }^{43}$ we proposed that substitution of the $\left[\mathrm{HSeO}_{3}\right]^{-}$units in $\mathbf{1}$ with monodentate anions (e.g. halides) is favorable for the formation of increased ionicity of $\mathrm{M}-\mathrm{F}$ bonds and lead to NCS materials with large SHG responses induced by the large hyperpolarizabilities of the distorted metal-oxygen/halogen polyhedra. In contrast, when $\left[\mathrm{HSeO}_{3}\right]^{-}$units are substituted by polydentate anions (e.g. $\left.\left[\mathrm{NO}_{3}\right]^{-},\left[\mathrm{SO}_{4}\right]^{2-},\left[\mathrm{BO}_{3}\right]^{3-}\right)$, the two distinct polydentate anions $\left[\mathrm{SeO}_{3}\right]^{2-}-\left[\mathrm{NO}_{3}\right]^{-} /\left[\mathrm{SO}_{4}\right]^{2-} /\left[\mathrm{BO}_{3}\right]^{3-}$ within the one molecular structure may result in antiparallel arrangements to improve local electroneutrality (energetically favorable from Pauling's Second Rule), affording centrosymmetric structures or weak SHG responses. ${ }^{44,45}$ 


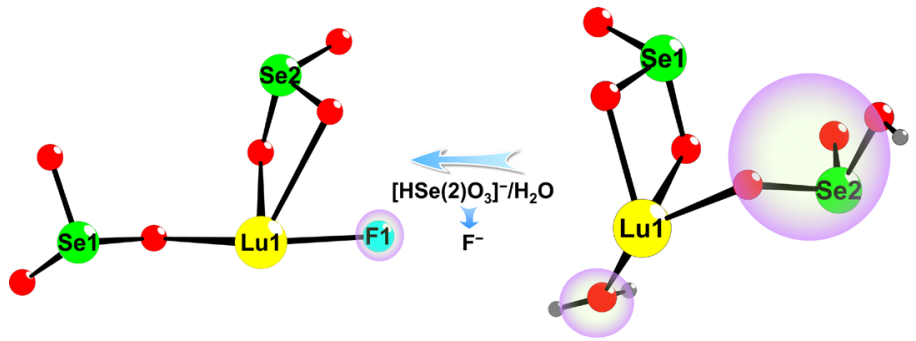

$\mathrm{Lu}_{3} \mathrm{~F}\left(\mathrm{SeO}_{3}\right)_{4} P 6_{3}$

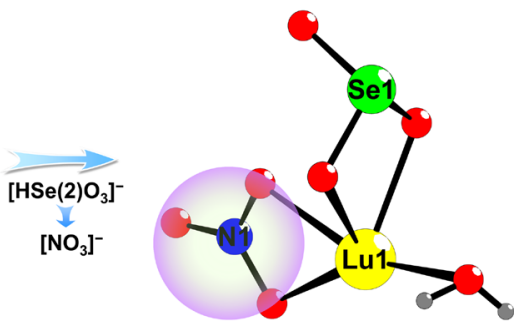

$\mathrm{Lu}\left(\mathrm{SeO}_{3}\right)\left(\mathrm{NO}_{3}\right)\left(\mathrm{H}_{2} \mathrm{O}\right) \mathrm{Pbcn}$

Figure 1. Schematic diagrams of asymmetric unit evolution among 1, 2,

and 3.

Guided by the above design ideas, two lutetium selenites with two distinct anions, polar $\mathrm{Lu}_{3} \mathrm{~F}\left(\mathrm{SeO}_{3}\right)_{4}$ (2) and $\mathrm{CS}$ $\mathrm{Lu}\left(\mathrm{SeO}_{3}\right)\left(\mathrm{NO}_{3}\right)\left(\mathrm{H}_{2} \mathrm{O}\right)$ (3), were successfully synthesized through substitution of $\left[\mathrm{HSeO}_{3}\right]^{-}$in $\mathbf{1}$ by either the monodentate $\mathrm{F}^{-}$anion or the polydentate $\left[\mathrm{NO}_{3}\right]^{-}$anion, respectively (Figure 1). 2 features a three-dimensional (3D) honeycomblike framework and exhibits excellent NLO properties, including a strong $\mathrm{SHG}$ response $\left(2.5 \times \mathrm{KH}_{2} \mathrm{PO}_{4}(\mathrm{KDP})\right)$, a wide band gap $(3.57 \mathrm{eV})$ and optical transparency window $(0.35-10.3 \mu \mathrm{m})$, high thermal stability $\left(\sim 550{ }^{\circ} \mathrm{C}\right)$, and a large laser damage threshold $\left(36 \times \mathrm{AgGaS}_{2}\right)$. In sharp contrast to 2, $\mathbf{3}$ exhibits a layered structure similar to that of $\mathbf{1}$ and displays no SHG response because of its intrinsic CS structure. Structure evolution analysis reveals that the denticity of the secondary functional anions has a significant influence on the coordination environments of the metal cation $\mathrm{Lu}^{3+}$, and consequently the molecular configuration of the resultant multidimensional selenites, which influences the NLO performance. The results confirm that crystal $\mathbf{2}$ may have potential application as an NLO material in the region between the near-ultraviolet and the mid-infrared (mid-IR), and that anion partial substitution (APS) is a feasible strategy for the preparation of NLO crystalline materials.

\section{EXPERIMENTAL SECTION}

Reagents. $\mathrm{Lu}\left(\mathrm{NO}_{3}\right)_{3} \cdot 6 \mathrm{H}_{2} \mathrm{O}(99.99 \%), \mathrm{CuO}(99.0 \%)$, and $\mathrm{SeO}_{2} \quad(99.8 \%)$ (Tansoole Chemical Reagent Co., Ltd), $\mathrm{NH}_{4} \mathrm{NO}_{3}$ (Tianjin Fuchen Reagent Company, 99.0\%) and $\mathrm{HF}$ (Tansoole Chemical Reagent Co., Ltd., 40\%) were obtained commercially and used as received. Caution! Hydrofluoric acid is toxic and corrosive! It must be handled with extreme caution and with the appropriate protective equipment and training.

Synthesis of 1. A mixture of $\mathrm{Lu}\left(\mathrm{NO}_{3}\right)_{3} \cdot 6 \mathrm{H}_{2} \mathrm{O}(0.720 \mathrm{~g}$, $1.50 \mathrm{mmol}), \mathrm{CuO}$ (0.040 g, $0.50 \mathrm{mmol}), \mathrm{SeO}_{2}(0.110 \mathrm{~g}, 1.00$ $\mathrm{mmol})$, and deionized water $(3 \mathrm{~mL})$ was sealed in a $20 \mathrm{~mL}$ autoclave equipped with a Teflon liner. The autoclave was

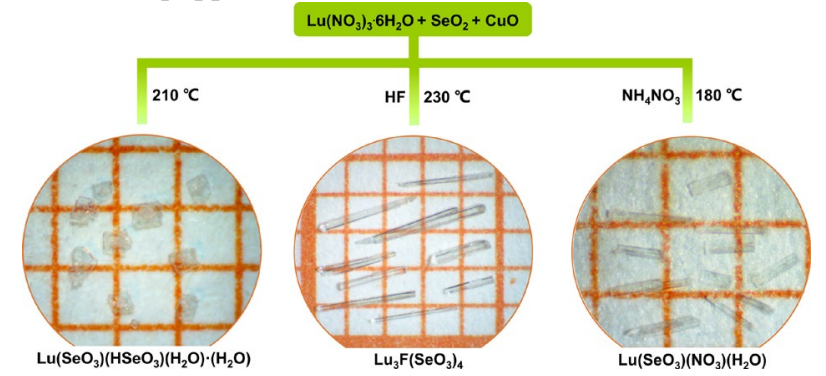

Figure 2. Schematic diagram of synthetic process of 1, 2, and 3 via mild hydrothermal methods (Each small cell stands for a millimeter). heated at $210{ }^{\circ} \mathrm{C}$ for $72 \mathrm{~h}$, and then slowly cooled to $30^{\circ} \mathrm{C}$ at 4 ${ }^{\circ} \mathrm{C} / \mathrm{h}$. After washing with deionized water, colorless plate-like crystals of 1 (Figure 2) were isolated using a microscope $(0.247 \mathrm{~g}, 53 \%$ based on $\mathrm{Se})$.

Synthesis of 2. A small amount of HF and a relatively high temperature were employed to synthesize the fluorinated rare-earth lutetium selenite 2 . The detailed synthetic route, adapted from the synthesis of $\mathbf{1}$, is as follows: $\mathrm{Lu}\left(\mathrm{NO}_{3}\right)_{3} \cdot 6 \mathrm{H}_{2} \mathrm{O}$ (0.720 g, $1.50 \mathrm{mmol}), \mathrm{CuO}(0.040 \mathrm{~g}, 0.50 \mathrm{mmol}), \mathrm{SeO}_{2}(0.110$ g, $1.00 \mathrm{mmol}), \mathrm{HF}(300 \mu \mathrm{L})$, and deionized water $(3 \mathrm{~mL})$ were sealed in the same autoclave as above, and the mixture was heated at $230{ }^{\circ} \mathrm{C}$ for $72 \mathrm{~h}$ with the other steps the same as described above, affording colorless rod-like crystals of 2 (Figure 2) ( $0.071 \mathrm{~g}, 27 \%$ based on Se).

Synthesis of 3. In order to introduce $\left[\mathrm{NO}_{3}\right]^{-}$into the rareearth lutetium selenite, $\mathrm{NH}_{4} \mathrm{NO}_{3}$ was employed to increase the concentration of nitrate in aqueous solution. The synthetic details, adapted from the synthesis of $\mathbf{1}$, are as follows: A mixture of $\mathrm{Lu}\left(\mathrm{NO}_{3}\right)_{3} \cdot 6 \mathrm{H}_{2} \mathrm{O}(0.720 \mathrm{~g}, 1.50 \mathrm{mmol}), \mathrm{CuO}(0.040 \mathrm{~g}$, $0.50 \mathrm{mmol}), \mathrm{SeO}_{2}(0.110 \mathrm{~g}, 1.00 \mathrm{mmol})$, and $\mathrm{NH}_{4} \mathrm{NO}_{3}(0.320$ $\mathrm{g}, 4.00 \mathrm{mmol})$ in deionized water $(3 \mathrm{~mL})$ was sealed in a 20 $\mathrm{mL}$ Teflon-lined stainless steel autoclave. The autoclave was heated at $180^{\circ} \mathrm{C}$ for $72 \mathrm{~h}$ and then cooled to room temperature at a rate of $3{ }^{\circ} \mathrm{C} / \mathrm{h}$. Colorless brick-shaped crystals of $\mathbf{3}$ (Figure 2) were obtained $(0.175 \mathrm{~g}, 46 \%$ based on $\mathrm{Se})$.

Structural determination. Single-crystal X-ray diffraction data of three crystals with dimensions of $0.17 \times 0.14 \times$ $0.08 \mathrm{~mm}^{3} \mathbf{1}, 0.22 \times 0.10 \times 0.08 \mathrm{~mm}^{3} 2$, and $0.20 \times 0.12 \times 0.07$ $\mathrm{mm}^{3} 3$ were collected at room temperature on a Bruker D8 VENTURE CMOS X-ray diffractometer using graphitemonochromated Mo-K $\alpha$ radiation $(\lambda=0.71073 \AA)$. Data collection and reduction were performed using APEX II software. Multi-scan absorption corrections were applied to data sets using the APEX II program. All three structures were solved by direct methods and refined on $F^{2}$ by full-matrix leastsquares methods using SHELXTL. ${ }^{46,47}$ All non-hydrogen atoms were refined anisotropically. $\mathrm{O}(1 \mathrm{~W})$ and $\mathrm{O}(2 \mathrm{~W})$ in $\mathbf{1}$ and $\mathrm{O}(1 \mathrm{~W})$ in 3 were assigned as $\mathrm{H}_{2} \mathrm{O}$ molecules, and $\mathrm{O}(6)$ in $\mathbf{1}$ was assigned as a hydroxyl group on the basis of the requirements of charge balance and bond valence calculations. The structures were verified using PLATON program, and no other higher symmetries were found. ${ }^{48}$ Table 1 summarizes the crystal data and structure refinement parameters of crystals 1-3. Selected bond distances $(\AA)$ and angles $\left(^{\circ}\right)$ of crystals 1-3 are collected in Tables S1-S3.

Powder XRD. Powder XRD data of 1-3 were recorded on a Bruker D8 Advance diffractometer using $\mathrm{Cu} \mathrm{K} \alpha(\lambda=1.5418$ $\AA)$ radiation, with a step size of $0.02^{\circ}$ in $2 \theta$ over a range of $5-70^{\circ}$, which confirmed the purities of the products (Figure S1). 
Table 1 Crystal data and structure refinement parameters for $1-\mathbf{3}^{\mathrm{a}}$

\begin{tabular}{|c|c|c|c|}
\hline formula & $\mathrm{Lu}\left(\mathrm{SeO}_{3}\right)\left(\mathrm{HSeO}_{3}\right)\left(\mathrm{H}_{2} \mathrm{O}\right) \cdot\left(\mathrm{H}_{2} \mathrm{O}\right)$ & $\mathrm{Lu}_{3} \mathrm{~F}\left(\mathrm{SeO}_{3}\right)_{4}$ & $\mathrm{Lu}\left(\mathrm{SeO}_{3}\right)\left(\mathrm{NO}_{3}\right)\left(\mathrm{H}_{2} \mathrm{O}\right)$ \\
\hline formula weight & 931.86 & 1051.75 & 381.96 \\
\hline temperature $(\mathrm{K})$ & 293(2) & 293(2) & 293(2) \\
\hline crystal system & orthorhombic & trigonal & orthorhombic \\
\hline space group & $P 2_{1} 2_{1} 2_{1}$ & $\mathrm{PG}_{3}$ & Pbcn \\
\hline$a(\AA)$ & $6.4728(4)$ & $9.883(3)$ & $16.151(8)$ \\
\hline$b(\AA)$ & $6.8453(5)$ & $9.883(3)$ & $11.854(5)$ \\
\hline$c(\AA)$ & $16.2422(11)$ & $7.066(2)$ & $6.795(4)$ \\
\hline$\alpha\left(^{\circ}\right)$ & 90 & 90 & 90 \\
\hline$\beta\left(^{\circ}\right)$ & 90 & 90 & 90 \\
\hline$\gamma\left({ }^{\circ}\right)$ & 90 & 120 & 90 \\
\hline $\mathrm{V}\left(\AA^{3}\right)$ & $719.66(8)$ & $597.7(3)$ & $1300.9(11)$ \\
\hline$Z$ & 2 & 2 & 8 \\
\hline$\rho_{\text {calc }}\left(\mathrm{g} \mathrm{cm}^{-3}\right)$ & 4.300 & 5.844 & 3.900 \\
\hline$\mu\left(\mathrm{mm}^{-1}\right)$ & 23.835 & 36.835 & 20.760 \\
\hline$F(000)$ & 832 & 908 & 1360 \\
\hline$\theta$ (deg.) & $3.23-27.07$ & $3.74-27.11$ & $3.68-26.42$ \\
\hline limiting indices & $\begin{array}{c}-6 \leq h \leq 8 \\
-8 \leq k \leq 7 \\
-20 \leq l \leq 20\end{array}$ & $\begin{array}{c}-10 \leq h \leq 12 \\
-12 \leq k \leq 11 \\
-9 \leq l \leq 9\end{array}$ & $\begin{array}{c}-19 \leq h \leq 20 \\
-14 \leq k \leq 14 \\
-7 \leq l \leq 8\end{array}$ \\
\hline$R_{\text {int }}$ & 0.0478 & 0.0388 & 0.0537 \\
\hline $\begin{array}{l}\text { no. of reflections } \\
\text { (collected/unique) }\end{array}$ & $3658 / 1567$ & $3017 / 877$ & $6179 / 1324$ \\
\hline goodness of fit on $F^{2}$ & 1.076 & 1.066 & 1.133 \\
\hline Flack factor & 0.00 & 0.00 & - \\
\hline$R_{1}, w R_{2}[\mathrm{I}>2 \sigma(\mathrm{I})]^{a}$ & $0.0377,0.0954$ & $0.0238,0.0550$ & $0.0485,0.1377$ \\
\hline$R_{1}, w R_{2}$ (all data) & $0.0416,0.0970$ & $0.0245,0.0554$ & $0.0586,0.1438$ \\
\hline $\begin{array}{l}\text { largest difference peak and hole (e } \\
\qquad \AA^{-3} \text { ) }\end{array}$ & 2.227 and -2.049 & 3.156 and -0.962 & 2.039 and -4.404 \\
\hline
\end{tabular}

IR Spectroscopy. The IR spectra of 1-3 were measured on a Nicolet 360 FT-IR instrument covering the wavenumber range 500-4000 $\mathrm{cm}^{-1}$. The samples were mixed thoroughly with dried $\mathrm{KBr}$ at a mass ratio of about 1:100 and were then pressed into transparent sheets for measurements.

UV-Vis-NIR Diffuse Reflectance Spectra. Optical diffuse reflectance spectra of 1-3 were measured at room temperature with a Cary 5000 UV-Vis-NIR spectrophotometer in the wavelength range $200-2500 \mathrm{~nm}$ at room temperature. Ba$\mathrm{SO}_{4}$ was used as a standard. Reflectance spectra were converted into absorbance using the Kubelka-Munk function. ${ }^{49}$

Thermal Analysis. The thermal behavior of 1-3 were investigated using a Netzsch STA 409PC thermal analyzer instrument at a heating rate of $15{ }^{\circ} \mathrm{C} / \mathrm{min}$ under nitrogen protection.

Second-Order NLO Measurements. The powder SHG responses of samples $\mathbf{1}$ and $\mathbf{2}$ were investigated using the Kurtz and Perry method. ${ }^{50}$ A 1064 nm Nd:YAG Q-switched laser was chosen as the light source. Because the SHG efficiency depends on particle size, crystalline compounds $\mathbf{1}$ and $\mathbf{2}$ were ground and sieved into several particle sizes $(<26$, 26-50, 50-74, 74-105, 105-150, 150-200 and 200-280 $\mu \mathrm{m})$, which were pressed into disks with diameters of $6 \mathrm{~mm}$ that were placed between glass microscope slides and secured with tape in a $1 \mathrm{~mm}$ thick aluminum holder. Crystalline KDP was also ground and sieved into the same particle size ranges and used as the reference.
Laser Damage Threshold (LDT) Measurement. The LDT tests ${ }^{51}$ were performed on powder samples of $\mathbf{1}$ and $\mathbf{2}$ with the particle size range of $105-150 \mu \mathrm{m}$, which were obtained by grinding single crystals. The radiation source was a laser of $1064 \mathrm{~nm}(10 \mathrm{~ns}, 1 \mathrm{~Hz})$. The energy of the laser emission was gradually increased until the color of the samples changed. $\mathrm{AgGaS}_{2}$ with the same particle size range (105-150 $\mu \mathrm{m})$ was chosen as the standard to test under the same conditions.

Calculation Details. All electronic structure calculations were performed using the VASP code ${ }^{52}$ within the framework of density functional theory (DFT). The generalized gradient approximation

(GGA) function of Perdew-Burke-Ernzerhof (PBE) $)^{53}$ was employed. A plane-wave basis set with a frozen-core projector-augmented wave $(\mathrm{PAW})^{54,55}$ potential and a plane-wave cutoff energy of $400 \mathrm{eV}$ was used. A grid of $5 \times 5 \times 4$ Monkhurst-Pack $k$-points was used for the self-consistent-field convergence of the total electronic energy. The Fermi level was set at zero as the energy reference. The contributions to the SHG susceptibility are the intraband transitions $\chi_{\text {intra }}(-2 \omega ; \omega$, $\omega)$, the interband transitions $\chi_{\text {inter }}(-2 \omega ; \omega, \omega)$, and the modulation terms $\chi_{\bmod }(-2 \omega ; \omega, \omega)$. These terms are calculated according to Eqns. (1)-(3) in Ref. 56, and then the SHG susceptibility tensors can be obtained by summing over these terms, where $W_{k}$ is the weight of the $k$ point, $n$ denotes the valence states, $m$ the conduction states, and $l$ denotes all states $(l \neq m$, $n)$. 


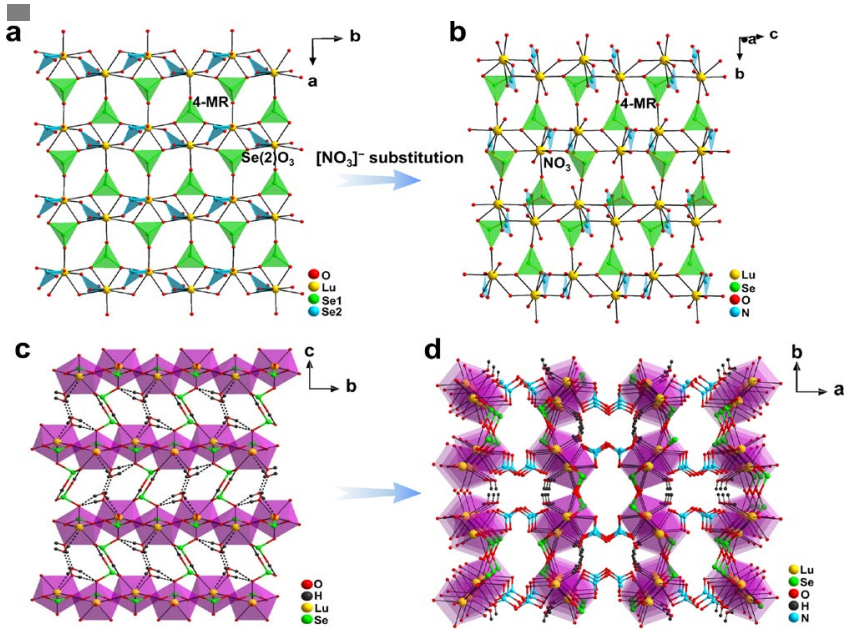

Figure 3. Comparison of crystal structures between $\mathbf{1}$ and $\mathbf{3}$. (a) View of the lutetium selenite layers containing 4-MR in $\mathbf{1}$. (b) View of the 2D lutetium selenite nitrate layer containing 4$\mathrm{MR}$ in 3. (c) View of the 3D supramolecular framework of 1 along the $a$-axis. (d) Perspective view of the 3D structure of 3 projected along the $c$-axis.

\section{RESULTS AND DISCUSSION}

Syntheses and Thermal Stabilities. Crystalline compounds $\mathbf{1}$ and $\mathbf{3}$ were prepared from the same reactants (ratio: $\left.\mathrm{Lu}\left(\mathrm{NO}_{3}\right)_{3} \cdot 6 \mathrm{H}_{2} \mathrm{O}: \mathrm{CuO}: \mathrm{SeO}_{2}=3: 1: 2\right)$ and conditions, except that on proceeding from 1 to 3 the reaction temperature was reduced from $210{ }^{\circ} \mathrm{C}$ to $180{ }^{\circ} \mathrm{C}$ and the nitrate concentration was increased by addition of a further 2.67 weight equivalent $\mathrm{NH}_{4} \mathrm{NO}_{3}\left(v s \mathrm{Lu}\left(\mathrm{NO}_{3}\right)_{3}\right)$ in aqueous solution. The $\left[\mathrm{HSeO}_{3}\right]^{-}$ groups in $\mathbf{1}$ and the $\mathrm{H}_{2} \mathrm{O}$ molecules in both $\mathbf{1}$ and $\mathbf{3}$ may be the cause of their poor

thermal stabilities (see below). The free $\mathrm{H}_{2} \mathrm{O}$ molecules in $\mathbf{1}$ afford hydrogen-bonding interactions between adjacent layers, which may be the reason why a "tight" 3D structure is observed for 1. No $\mathrm{OH}^{-}$group or $\mathrm{H}_{2} \mathrm{O}$ molecules exist in the structure of 2; the synthesis employs a higher temperature $\left(230{ }^{\circ} \mathrm{C}\right)$ and more reaction media $(3 \mathrm{~mL}$ of distilled water and $300 \mu \mathrm{L}$ of $\mathrm{HF}$ ), disfavoring the incorporation of these units and giving the highly polymeric honeycomb-like framework of 2 . It is noteworthy that using a small amount of $\mathrm{CuO}$ can increase the yield of the target compounds. In order to understand the influence of the reaction temperature and the secondary functional anions on the syntheses of 1-3 (and while maintaining the amount and nature of the reaction media (deionized water and $\mathrm{HF}$ )), the reaction temperatures used for $\mathbf{1}$ and $3\left(210^{\circ} \mathrm{C}\right.$ and $180{ }^{\circ} \mathrm{C}$, respectively) were employed in an attempt to synthesize $\mathbf{2}$, but no crystal of $\mathbf{2}$ was obtained. We also explored the use of the synthesis temperature for $\mathbf{2}$ (but without HF) in an attempt to prepare $\mathbf{1}$ and $\mathbf{3}$, but only a small amount of $\mathbf{1}$ and no $\mathbf{3}$ were achieved. In addition, our synthesis attempts with three types of NLO-active anions in the Lu$\mathrm{SeO}_{3}-\mathrm{NO}_{3}-\mathrm{F}$ ternary system at three different temperatures were also unsuccessful, only $1\left(180^{\circ} \mathrm{C}, 210^{\circ} \mathrm{C}, 230^{\circ} \mathrm{C}\right)$ and 3 $\left(180{ }^{\circ} \mathrm{C}, 210^{\circ} \mathrm{C}\right)$ being isolated. These results indicate that $\mathrm{F}^{-}$ and $\left[\mathrm{NO}_{3}\right]^{-}$anions exhibit competition in lutetium selenite reactions, higher temperatures favoring introduction of fluorine into lutetium selenite and lower temperatures being conducive to the introduction of nitrate.

Thermogravimetric analysis indicates that 1, 2, and 3 exhibit completely different thermal behavior. $\mathbf{1}$ is thermally stable to $90{ }^{\circ} \mathrm{C}$ only (Figure S2a), understandable because of the presence of one bound-water molecule. Above this temperature, the thermal decomposition of $\mathbf{1}$ involves two weightloss steps. An initial weight loss of $9.42 \%$ is observed between $90{ }^{\circ} \mathrm{C}$ and $300{ }^{\circ} \mathrm{C}$, which corresponds to the removal of $5 \mathrm{H}_{2} \mathrm{O}$ molecules (calculated value: $9.67 \%$ ). The second weight loss (46.93\%) occurs between $480{ }^{\circ} \mathrm{C}$ and $860{ }^{\circ} \mathrm{C}$, which is attributable to the elimination of $4 \mathrm{SeO}_{2}$ (calculated value: $47.63 \%$ ). The TGA curve (Figure S2c) of 3 also exhibits a two-step weight loss; the minor weight loss of $4.65 \%$ (calculated value $4.72 \%$ ) in the range $200-300{ }^{\circ} \mathrm{C}$ is due to the loss of $\mathrm{H}_{2} \mathrm{O}$, while in the second stage $\left(350-880{ }^{\circ} \mathrm{C}\right)$, the weight loss is tentatively attributed to the release of $\mathrm{NO}, \mathrm{O}_{2}$ and $\mathrm{SeO}_{2}$. The observed weight loss of $44.56 \%$ for 3 matches the calculated value $(45.28 \%)$. In sharp contrast to $\mathbf{1}$ and $\mathbf{3}, \mathbf{2}$ is thermally stable up to $550{ }^{\circ} \mathrm{C}$ (Figure S2b), which is significantly higher than most reported metal selenites, (e.g. $\mathrm{Pb}_{3}\left(\mathrm{SeO}_{3}\right) \mathrm{Br}_{4}$ $\left(230{ }^{\circ} \mathrm{C}\right),{ }^{33} \mathrm{BiFSeO}_{3}\left(300{ }^{\circ} \mathrm{C}\right),{ }^{30} \mathrm{BaBi}\left(\mathrm{SeO}_{3}\right)_{2} \mathrm{Cl}\left(300{ }^{\circ} \mathrm{C}\right),{ }^{34}$ $\mathrm{Rb}_{2} \mathrm{SeOCl}_{4} \cdot \mathrm{H}_{2} \mathrm{O}\left(80{ }^{\circ} \mathrm{C}\right),{ }^{57}$ and $\left.\mathrm{Bi}\left(\mathrm{SeO}_{3}\right)\left(\mathrm{HSeO}_{3}\right)^{58}\right) .2$ quickly loses weight in the temperature region $560-840{ }^{\circ} \mathrm{C}$, showing one sharp weight-loss step that corresponds to the removal of $\mathrm{F}_{2}$ and $\mathrm{SeO}_{2}$ (calculated value $44.01 \%$ ).

Structure Description. Crystal Structure of 1. Singlecrystal X-ray structure analysis reveals that $\mathbf{1}$ crystallizes in the orthorhombic crystal system in the chiral space group $P 2_{1} 2_{1} 2_{1} \quad$ (No. 19), which is isostructural to $\left(\mathrm{Ln}\left(\mathrm{SeO}_{3}\right)\left(\mathrm{HSeO}_{3}\right)\left(\mathrm{H}_{2} \mathrm{O}\right) \cdot\left(\mathrm{H}_{2} \mathrm{O}\right)\left(\mathrm{Ln}=\mathrm{Nd},{ }^{59} \mathrm{Y},{ }^{60} \mathrm{Sm}^{61}\right)\right.$. Within the asymmetric unit of $1, \mathrm{Lu}, \mathrm{Se}, \mathrm{O}$ and $\mathrm{H}$ atoms occupy one, two, eight and five unique sites, respectively (Figure 1). The eight-coordinate $\mathrm{Lu}^{3+}$ cation is attached to eight oxygen atoms (one selenite group in a bidentate chelating fashion, five selenite groups in a unidentate chelating mode, and one $\mathrm{H}_{2} \mathrm{O}$ molecule), forming a $\mathrm{LuO}_{8}$ polyhedron (Figure S3a). The $\mathrm{Lu}-\mathrm{O}$ distances range from $2.222(8)$ to $2.392(9) \AA$. Each $\mathrm{Se}^{4+}$ cation is coordinated by three $\mathrm{O}$ atoms, resulting in a trigonal pyramidal geometry with angles of $92.3(4)-104.1(4)^{\circ}$. The $\mathrm{Se}-\mathrm{O}$ bond lengths are in the range $1.663(8)-1.755(10) \AA$. The $\left[\mathrm{Se}(1) \mathrm{O}_{3}\right]^{2-}$ group exhibits bidentate chelation to one $\mathrm{Lu}$ $(\mathrm{O}(4)$ and $\mathrm{O}(5))$ atom and bridges three other $\mathrm{Lu}$ atoms. The $\left[\mathrm{HSe}(2)_{3}\right]^{-}$group bridges two Lu atoms (Figure $\mathrm{S} 3 \mathrm{e}$ ). In the structure of 1, all of the lone pairs of electrons of the $\left[\mathrm{SeO}_{3}\right]^{2-}$ groups are aligned antiparallel, resulting in a macroscopic dipole moment that is not favorable for the generation of significant SHG response (Figure S3b). Bond valence sum (BVS) calculations $^{62}$ yield $3.09,4.16$ and 4.00 for $\operatorname{Lu}(1), \operatorname{Se}(1)$ and $\operatorname{Se}(2)$, respectively.

As seen in Figure $\mathrm{S} 3 \mathrm{c}$, the $\mathrm{LuO}_{8}$ and $\mathrm{Se}(2) \mathrm{O}_{3}$ polyhedra share their edges and corners and generate an infinite chain along the $b$-axis. The $\left[\mathrm{Se}(2) \mathrm{O}_{3}\right]^{2-}$ groups link two $\mathrm{Lu}$ atoms via bonds to $\mathrm{O}$ atoms, while the third $\mathrm{O}$ atom $(\mathrm{O}(6))$ remains non-coordinated. The infinite chains are further linked by $\left[\mathrm{Se}(1) \mathrm{O}_{3}\right]^{2-}$ groups, affording a lamellar structure with 4membered-rings (4-MRs) in the $a b$ plane (Figure 3a). The $\mathrm{Lu}^{\cdots} \mathrm{Lu}$ and $\mathrm{Se}{ }^{\cdots}$ Se distances in the 4-MR are $6.05 \AA$ and 4.01 $\AA$ (Figure S3d), respectively. The layers are parallel stacked along the $c$-axis and linked to each other by $\mathrm{O}-\mathrm{H} \cdots \mathrm{O} \mathrm{H}$-bonds (Table S4), which eventually leads to a 3D framework structure with $\mathrm{H}_{2} \mathrm{O}$ molecules located between the interlayers (Figure $3 \mathrm{c}$ ).

Crystal Structure of 2.2 is the first example of a fluorinated lutetium selenite: it crystallizes in the polar and chiral hexagonal space group $P 6_{3}$ (No. 173) with $\mathrm{Z}=2$, which reveals a partially similar structure to those of $\mathrm{Ln}_{3} \mathrm{~F}\left(\mathrm{SeO}_{3}\right)_{4}(\mathrm{Ln}$ 

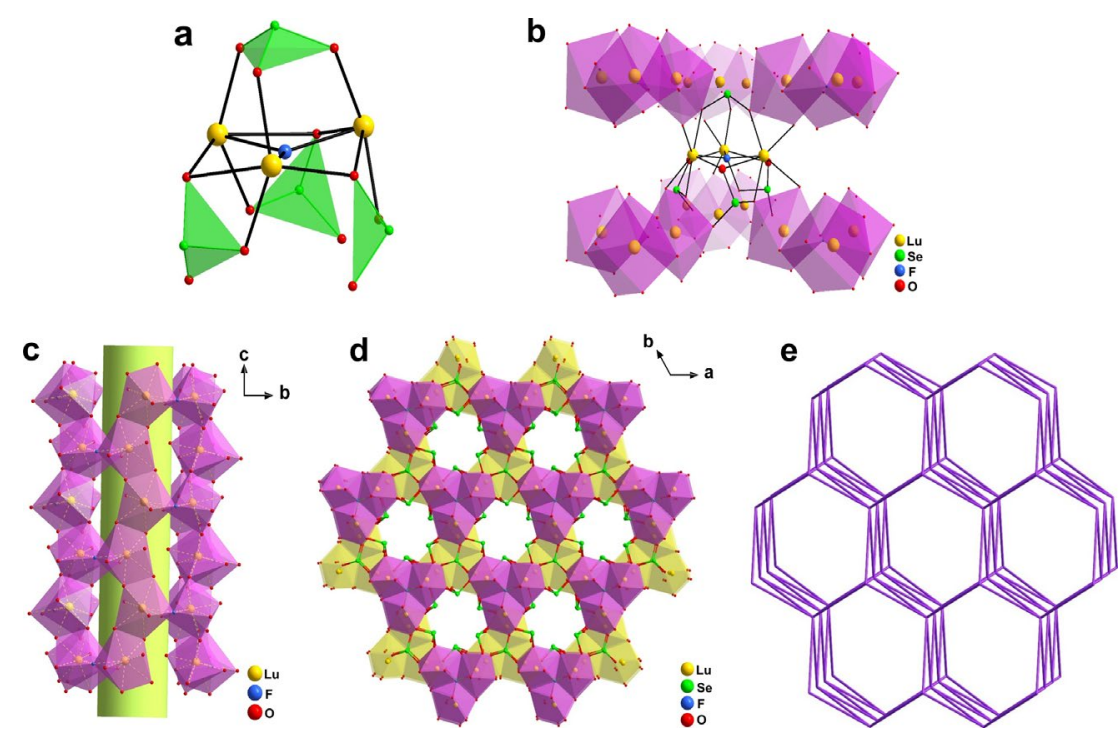

Figure 4. (a) $\mathrm{Lu}_{3}\left(\mu_{3}-\mathrm{F}\right)\left(\mathrm{SeO}_{3}\right)_{4}$ cluster unit. (b) View of the linkage of $\mathrm{Lu}_{3} \mathrm{~F}\left(\mathrm{SeO}_{3}\right)_{4}$ cluster units. (c) View of the 12-MR channel in 2. (d) Framework structure of $\mathbf{2}$ viewed along the $c$-axis showing the 12-MR channels. (e) View of the topology network in $\mathbf{2}$.

$=\mathrm{Gd},{ }^{63} \mathrm{Dy},{ }^{64}$ and $\left.\mathrm{Ho}^{65}\right)$. In the crystal structure of $\mathbf{2}$, the primary building unit (PBU) $\mathrm{Lu}_{3}\left(\mu_{3}-\mathrm{F}\right)\left(\mathrm{SeO}_{3}\right)_{4}$ is composed of four $\left[\mathrm{SeO}_{3}\right]^{2-}$ anions and a trinuclear $\mathrm{Lu}_{3} \mathrm{~F}$ unit (Figure $4 \mathrm{a}$ ). Each $\mathrm{Lu}_{3}\left(\mu_{3}-\mathrm{F}\right)\left(\mathrm{SeO}_{3}\right)_{4} \mathrm{PBU}$ is attached to six adjacent PBUs via $\mathrm{O}-\mathrm{Se}-\mathrm{O}$ and $\mathrm{Lu}-\mathrm{O}$ linkages (Figure $4 \mathrm{~b}$ ). Further connectivity of the $\mathrm{Lu}_{3}\left(\mu_{3}-\mathrm{F}\right)\left(\mathrm{SeO}_{3}\right)_{4}$ PBUs through their edges and vertices yields a $3 \mathrm{D}$ framework with $12-\mathrm{MR}$ channels along the $c$-axis (Figures $4 \mathrm{c}$ and $4 \mathrm{~d}) .2$ can be reduced to an acs net topology $\left(4^{9} \cdot 6^{6}\right)$ with each $\mathrm{Lu}_{3}\left(\mu_{3}-\mathrm{F}\right)\left(\mathrm{SeO}_{3}\right)_{4} \mathrm{PBU}$ acting as a six-connected node (Figure 4e).

The asymmetric unit of 2 contains $1 \mathrm{Lu}, 2 \mathrm{Se}, 1 \mathrm{~F}$ and $4 \mathrm{O}$ atoms (Figure 1). Each $\mathrm{Lu}^{3+}$ cation is coordinated by one $\mathrm{F}$ atom, five $\mathrm{O}$ atoms from five selenite groups in a unidentate fashion, and two $\mathrm{O}$ atoms from one selenite group in a bidentate manner, forming a $\mathrm{LuO}_{7} \mathrm{~F}$ distorted bicapped trigonal prism (Figure $\mathrm{S} 4 \mathrm{a}$ ). The $\mathrm{Lu}-\mathrm{O}$ bond distances vary from $2.185(7)$ to $2.871(8) \AA$, while the $\mathrm{Lu}-\mathrm{F}$ bond distance is $2.2713(13) \AA$. The two Se atoms are found in highly asymmetric coordination environments that are attributable to their stereochemically-active lone pairs, each of them being bonded to three $\mathrm{O}$ atoms with $\mathrm{Se}-\mathrm{O}$ bond distances of 1.664(7)-1.710(6) $\AA$. The $\left[\mathrm{Se}(1) \mathrm{O}_{3}\right]^{2-}$ group bridges six $\mathrm{Lu}(1)$ atoms, while the $\left[\mathrm{Se}(2) \mathrm{O}_{3}\right]^{2-}$ group chelates to one $\mathrm{Lu}(1)$ atom and bridges three other $\mathrm{Lu}(1)$ atoms (Figure $\mathrm{S} 4 \mathrm{c}$ ). The lone pairs on the $\left[\mathrm{Se}(1) \mathrm{O}_{3}\right]^{2-}$ groups in $\mathbf{2}$ are aligned parallel to the $c$-axis, which is very beneficial for enhancing NLO susceptibilities (indeed, it is close to the maximum possible contribution to the macroscopic SHG effect: Figure S4b). BVS calculations afford values of 3.10, 4.00, and 4.21 for $\mathrm{Lu}(1)$, $\mathrm{Se}(1)$ and $\mathrm{Se}(2)$, respectively.

We also compared the structure of $\mathbf{2}$ with that of $\mathrm{Gd}_{3}\left(\mathrm{SeO}_{3}\right)_{4} \mathrm{~F}$. ${ }^{63}$ Each Lu atom in 2 is coordinated with $1 \mathrm{~F}$ and $7 \mathrm{O}$ atoms, while every $\mathrm{Gd}$ atom in $\mathrm{Gd}_{3}\left(\mathrm{SeO}_{3}\right)_{4} \mathrm{~F}$ is coordinated with $1 \mathrm{~F}$ and $8 \mathrm{O}$ atoms (Figures $\mathrm{S} 5 \mathrm{a}$ and $\mathrm{S} 5 \mathrm{~b}$ ). With respect to the coordination environments of $\left[\mathrm{SeO}_{3}\right]^{2-}$ groups, the $\left[\mathrm{Se}(2) \mathrm{O}_{3}\right]^{2-}$ group in 2 chelates to one $\mathrm{Lu}(1)$ atom and bridges three other $\mathrm{Lu}(1)$ atoms, while the $\left[\mathrm{Se}(2) \mathrm{O}_{3}\right]^{2-}$ group in $\mathrm{Gd}_{3}\left(\mathrm{SeO}_{3}\right)_{4} \mathrm{~F}$ differs from that in $\mathbf{2}$, chelating in a bidentate manner with two $\operatorname{Ln}(1)$ atoms and bridging two $\operatorname{Ln}(1)$ atoms (Figures $\mathrm{S} 5 \mathrm{c}$ and $\mathrm{S} 5 \mathrm{~d}$ ). Unlike the $\mathrm{Gd}_{3}\left(\mu_{3}-\mathrm{F}\right)\left(\mathrm{SeO}_{3}\right)_{4}$ cluster unit, the configuration of $\mathrm{Lu}_{3}\left(\mu_{3}-\mathrm{F}\right)\left(\mathrm{SeO}_{3}\right)_{4}$ cluster unit is more distorted owing to the different coordination environments between metal cations and $\left[\mathrm{Se}(2)_{3}\right]^{2-}$ anionic groups (Figures $\mathrm{S} 5 \mathrm{e}$ and $\mathrm{S} 5 \mathrm{f}$ ). Close structural investigations indicate that the size of rare-earth cations strongly influences the coordination modes of the $\left[\mathrm{SeO}_{3}\right]^{2-}$ groups and the subsequent configurations of the cluster units $\mathrm{Ln}_{3}\left(\mu_{3}-\mathrm{F}\right)\left(\mathrm{SeO}_{3}\right)_{4}$.

Crystal Structure of 3. 3 is the first lutetium selenite containing $\pi$-conjugated planar triangular anions. It crystallizes in the ortho rhombic crystal system in the centrosymmetric space group Pbcn (No. 60). The asymmetric unit of 3 contains one $\mathrm{Lu}^{3+}$ cation, one $\left[\mathrm{SeO}_{3}\right]^{2-}$ anion, one $\left[\mathrm{NO}_{3}\right]^{-}$anion and one $\mathrm{H}_{2} \mathrm{O}$ molecule (Figure 1). The $\mathrm{Lu}(1)^{3+}$ cation is coordinated with $8 \mathrm{O}$ atoms, forming a $\mathrm{LuO}_{8}$ dodecahedron with the $\mathrm{Lu}-\mathrm{O}$ distances ranging from 2.172(10) to 2.481(12) A (Figure S6a). Each $\mathrm{Lu}(1)^{3+}$ cation is connected to three $\left[\mathrm{SeO}_{3}\right]^{2-}$ anions that are bound in a unidentate fashion, one $\left[\mathrm{SeO}_{3}\right]^{2-}$ and one $\left[\mathrm{NO}_{3}\right]^{-}$anion attached in a bidentate chelating mode, and one $\mathrm{H}_{2} \mathrm{O}$ molecule. The $\mathrm{Se}(1)$ atom is bonded to three $\mathrm{O}$ atoms and possesses a trigonal pyramidal geometry. The $\left[\mathrm{Se}(1) \mathrm{O}_{3}\right]^{2-}$ group exhibits bidentate chelation to one $\mathrm{Lu}(\mathrm{O}(4)$ and $\mathrm{O}(5))$ atom and bridges three other $\mathrm{Lu}$ atoms (Figure S6e). The $\mathrm{Se}-\mathrm{O}$ distances range from $1.641(10)$ to $1.753(10) \AA$ and the $\mathrm{O}-\mathrm{Se}-\mathrm{O}$ bond angles are $91.0(5)-104.2(5)^{\circ}$ for the $\mathrm{SeO}_{3}$ trigonal pyramids, while the $\mathrm{N}-\mathrm{O}$ bond lengths are in the range $1.22(3)$ to $1.27(2) \AA$ and the $\mathrm{O}-\mathrm{N}-\mathrm{O}$ bond angles are $116.4(15)-123(2)^{\circ}$ for the $\mathrm{NO}_{3}$ triangles. The local dipole moments of the $\left[\mathrm{SeO}_{3}\right]^{2-}$ groups and $\left[\mathrm{NO}_{3}\right]^{-}$groups point in opposite direction, which leads to a nonpolar centrosymmetric structure for 3. BVS calculations for $\mathrm{Lu}(1), \mathrm{Se}(1)$, and $\mathrm{N}(1)$ are $3.23,4.24$, and 4.91, respectively.

Each $\mathrm{LuO}_{6}\left(\mathrm{NO}_{3}\right)$ unit shares an edge with the adjacent $\mathrm{LuO}_{6}\left(\mathrm{NO}_{3}\right)$ units, forming a novel infinite chain along the $c$ axis (Figure S6b). Each $\left[\mathrm{N}(1) \mathrm{O}_{3}\right]^{-}$group in $\mathbf{3}$ is bidentate, ligating with one $\mathrm{Lu}$ atom via two of its $\mathrm{O}$ atoms while the third $\mathrm{O}$ atom $(\mathrm{O}(2))$ remains non-coordinated. The adjacent chains are further bridged by $\left[\mathrm{Se}(1) \mathrm{O}_{3}\right]^{2-}$ groups to give twodimensional (2D) lutetium selenite nitrate layers with 4-MR parallel to the $b c$ plane (Figure $3 \mathrm{~b}$ and Figure S6c). As a result, the structure of $\mathbf{3}$ can also be described as the stacking of lutetium selenite nitrate lamellas along the $c$-axis (Figure $3 \mathrm{~d}$ ). There are weak hydrogen bonds between the $\left[\mathrm{NO}_{3}\right]^{-}$groups 


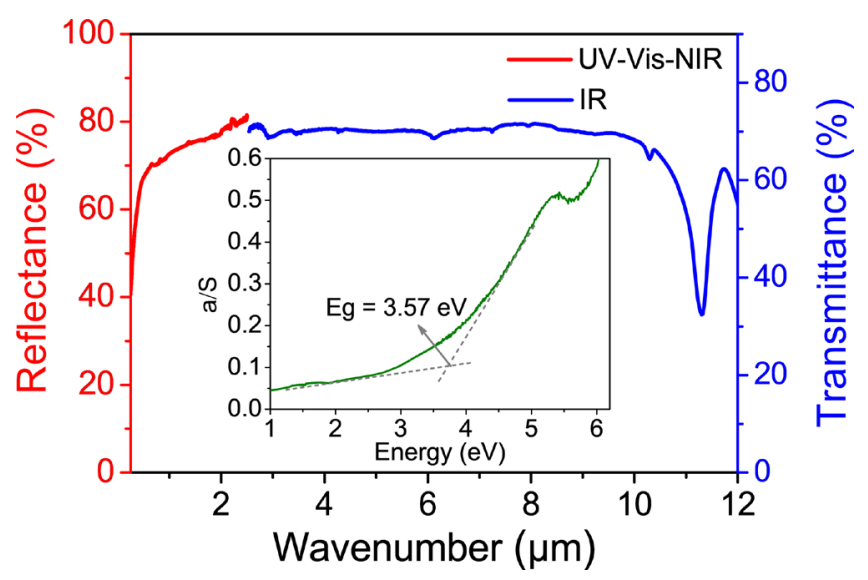

Figure 5. Optical properties of 2. The insert shows the corresponding band gap.

and the coordinated $\mathrm{H}_{2} \mathrm{O}$ molecules, with $\mathrm{O} \cdots \mathrm{O}$ distances of $2.7913 \AA$ (Figure S6d and Table S5).

IR Measurements. The IR spectra of the three crystalline compounds 1-3 are shown in Figure S7, and the infrared vibrations and assignments are listed in Table S6. The IR absorption bands of $\mathbf{1}-\mathbf{3}$ at $500-520$ and $692-850 \mathrm{~cm}^{-1}$ are attributable to the $\mathrm{Lu}-\mathrm{O}$ and $\mathrm{Se}-\mathrm{O}$ vibrations, respectively. The broad absorption bands for $\mathbf{1}$ at ca. 3519, 3122, 1641, and $1384 \mathrm{~cm}^{-1}$ confirm the presence of $[\mathrm{OH}]^{-}$groups and $\mathrm{H}_{2} \mathrm{O}$ molecules. The characteristic band at $1220 \mathrm{~cm}^{-1}$ is ascribed to the $\mathrm{Se}-\mathrm{O}$ bond in the $\left[\mathrm{HSeO}_{3}\right]^{-}$group. Similar to $\mathbf{1}$, the bands at 3380,1644 and $1500 \mathrm{~cm}^{-1}$ in the IR spectrum of $\mathbf{3}$ strongly suggest the presence of $\mathrm{H}_{2} \mathrm{O}$ molecules. The asymmetric and symmetric stretching vibrations of the $\left[\mathrm{NO}_{3}\right]^{-}$groups are observed at $1396-808 \mathrm{~cm}^{-1}$. The $\mathrm{Lu}-\mathrm{F}$ vibrations for 2 overlap with those of the $\mathrm{Se}-\mathrm{O}$ bond at $744 \mathrm{~cm}^{-1} .2$ is transparent in the region $2.5-10.3 \mu \mathrm{m}\left(4000-970 \mathrm{~cm}^{-1}\right.$ : Figure 5).

UV-Vis-NIR Diffuse Reflectance Spectra. The UV-VisNIR diffuse reflectance spectra for the three crystalline compounds are shown in Figure S8. Absorption data were calculated employing the Kubelka-Munk function: $F(R)=$ $(1-R)^{2} / 2 R=K / S$. 1, 2, and $\mathbf{3}$ have wide band-gap energies of $3.88,3.57$ and $4.03 \mathrm{eV}$, respectively. These are larger band gaps than that of the commercially available IR NLO crystal $\mathrm{AgGaS}_{2}(2.56 \mathrm{eV})$, implying that the above three NLO crystals may possess larger LDTs than that of $\mathrm{AgGaS}_{2}$. UV cutoff edges of 320, 347 and $308 \mathrm{~nm}$ are observed for $\mathbf{1 , 2}$, and 3, respec-

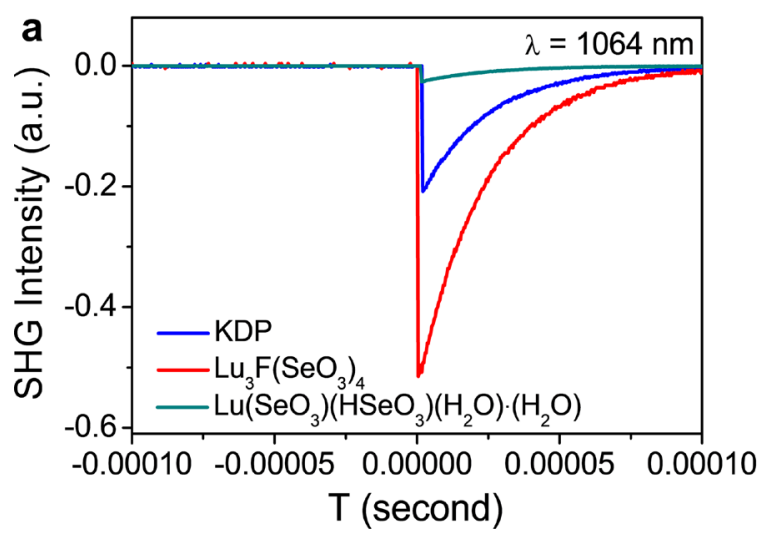

Figure 6. (a) Oscilloscope traces of the SHG signals for powders of 1, 2, and KDP in the same particle size range of $105-150 \mu \mathrm{m}$. (b) Phase-matching curve of 2 with $1064 \mathrm{~nm}$ laser radiation. KDP was used as a reference for the SHG measurement at $1064 \mathrm{~nm}$. tively. Thus, $\mathbf{1}$ and $\mathbf{3}$ are transparent in the regions $0.32-2.7$ and $0.31-2.7 \mu \mathrm{m}$, while 2 is transparent in the region $0.35-10.3 \mu \mathrm{m}$ (Figure 5), covering the near-UV to mid-IR.

LDT Measurements. As crystalline 1 and 2 possess large band gaps, LDT measurements were performed using $\mathrm{AgGaS}_{2}$ as the reference. The results reveal powder LDT values of 81 and $66 \mathrm{MW} / \mathrm{cm}^{2}$ for 1 and 2, respectively, which are 45 and 36 times larger than that of $\mathrm{AgGaS}_{2}\left(1.8 \mathrm{MW} / \mathrm{cm}^{2}\right)$. Under the same measurement conditions, the powder LDT value of 79 $\mathrm{MW} / \mathrm{cm}^{2}$ for $\mathrm{BiFSeO}_{3}{ }^{30}$ was also obtained, which is slightly weaker than that of $\mathbf{1}$ but larger than that of $\mathbf{2}$, consistent with their observed band gaps.

SHG Properties. As $\mathbf{1}$ and $\mathbf{2}$ crystallize with NCS structures, SHG measurements were performed using a $1064 \mathrm{~nm}$ Qswitched Nd:YAG laser. 1 displays a weak SHG response of ca. 0.1 times that of KDP (105-150 $\mu \mathrm{m}$ particle size range) (Figure 6a). Such a weak SHG response may be due to the cancellation of the polarizations from the $\left[\mathrm{SeO}_{3}\right]^{2-}$ groups (Figure S3b). 2 is a phase-matching NLO material according to Kurtz and Perry's definition (Figure 6b). ${ }^{41}$ Comparison of the SHG responses generated by crystalline 2 and KDP with identical size particles $(105-150 \mu \mathrm{m})$ reveals that $\mathbf{2}$ exhibits a strong SHG effect of about $2.5 \times \mathrm{KDP}$ (Figure $6 \mathrm{a}$ ); to the best of our knowledge, this is the highest value among rare-earthmetal-based NLO selenites (Table S7). Such a SHG efficiency of $\mathbf{2}$ is significantly larger than those of other metal selenites constructed with two types of anions (e.g. $\mathrm{RbSe}_{3} \mathrm{~B}_{2} \mathrm{O}_{9}(\mathrm{OH})$ $(0.4 \times \mathrm{KDP}),{ }^{66} \mathrm{CsSe}_{3} \mathrm{~B}_{2} \mathrm{O}_{9}(\mathrm{OH}) \quad(0.8 \times \mathrm{KDP}),{ }^{66}$ and $\left.\mathrm{Pb}_{2}\left(\mathrm{SeO}_{3}\right)\left(\mathrm{NO}_{3}\right)_{2}(2 \times \mathrm{KDP})^{67}\right)$.

Anion Partial Substitution $\left(\left[\mathrm{HSeO}_{3}\right]^{-}\right.$with $\mathbf{F}^{-}$or $\left.\left[\mathrm{NO}_{3}\right]^{-}\right)$for the Modulation of Structures, Macroscopic Centricities, and SHG Effects. Compounds 1-3 have a similar composition, including rare-earth-based counter-cation $\mathrm{Lu}^{3+}$ and NLO-active anion $\left[\mathrm{SeO}_{3}\right]^{2-}$, but they exhibit distinct centricities. The latter can be attributed to the different secondary functional anions and the flexible coordination modes of the rare-earth cation $\mathrm{Lu}^{3+}$. Interesting structural transformations occur in the lutetium selenite system with the substitution of the anions, proceeding from $\mathrm{H}_{2} \mathrm{O} /\left[\mathrm{HSeO}_{3}\right]^{-}$to $\mathrm{F}^{-}$and $\left[\mathrm{NO}_{3}\right]^{-}$. These three compounds crystallize in different space groups (1: $\left.P 2{ }_{1} 2_{1} 2_{1} ; 2: P 6_{3} ; 3: P b c n\right)$, although all $\mathrm{Lu}$ atoms are eight-coordinate. With respect to their asymmetric units, the coordination environment of the $\mathrm{Lu}$ atom in 3 can be viewed as the replacement of the $\left[\mathrm{HSeO}_{3}\right]^{-}$in 1 by the polydentate $\left[\mathrm{NO}_{3}\right]^{-}$anion, while the environment of the Lu atom in 2 corresponds to the substitution of coordinated $\mathrm{H}_{2} \mathrm{O} /\left[\mathrm{HSeO}_{3}\right]^{-}$by

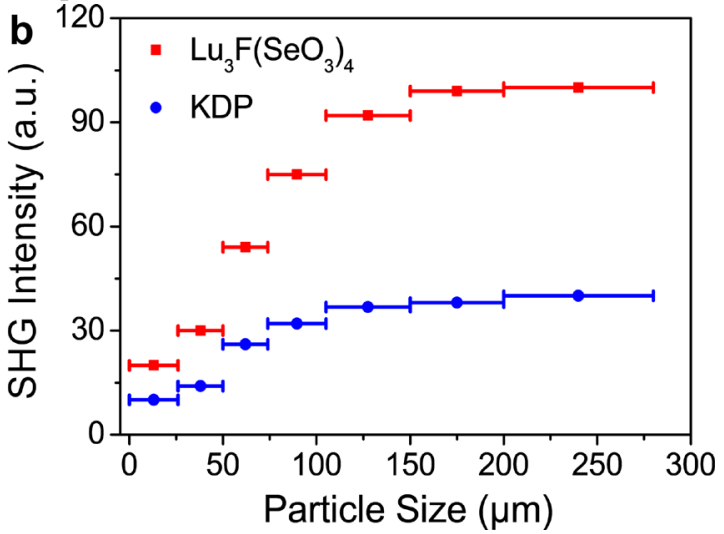



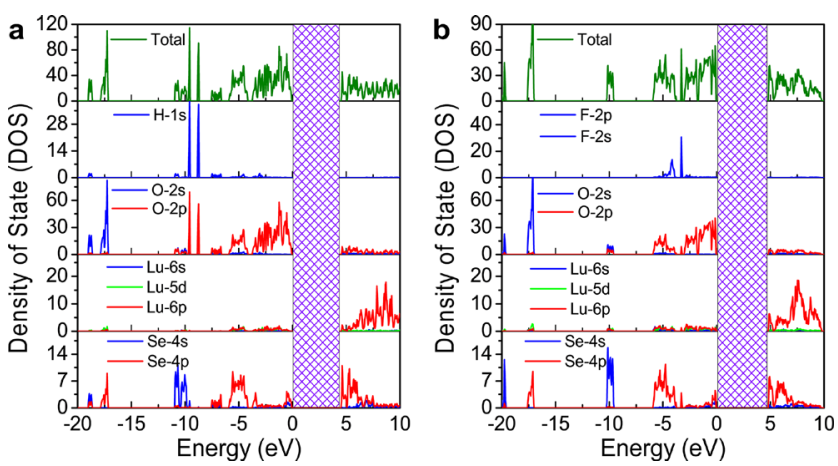

Figure 7. Total density of states (DOS) and partial density of states (PDOS) of $\mathbf{1}$ (a) and $\mathbf{2}$ (b); Fermi levels (dotted lines) located at zero.

$\mathrm{F}^{-}$anions (Figure 1). When the $\left[\mathrm{HSe}(2) \mathrm{O}_{3}\right]^{-}$anions are substituted by $\left[\mathrm{NO}_{3}\right]^{-}$groups, the 3D framework of 1 transforms into the 2D-layered 3. Although 1 crystallizes in an NCS space group, the almost antiparallel arrangement of the lone pairs on the $\left[\mathrm{SeO}_{3}\right]^{2-}$ groups results in a very weak $\mathrm{SHG}$ response. With 3 , the $\pi$-conjugated $\left[\mathrm{NO}_{3}\right]^{-}$groups are arranged antiparallel, the lone pairs of the adjacent $\mathrm{Se}^{4+}$ cations being oriented in opposite directions, which leads to the formation of a CS structure. A smaller interlayer spacing of $8.08 \AA$ in 3 than that of $8.12 \AA$ in 1 is observed, due to the relatively small $\left[\mathrm{NO}_{3}\right]^{-}$ groups instead of $\left[\mathrm{HSeO}_{3}\right]^{-}$anions filling the spaces between adjacent layers (Figure S9). The introduction of the $\mu_{3}$-linkage of the $\mathrm{F}^{-}$anions leads to the formation of the $\mathrm{Lu}_{3}\left(\mu_{3}-\mathrm{F}\right)\left(\mathrm{SeO}_{3}\right)_{4}$ $\mathrm{PBU}$ in 2. The $\left[\mathrm{Se}(1) \mathrm{O}_{3}\right]^{2-}$ groups in the $\mathrm{Lu}_{3}\left(\mu_{3}-\mathrm{F}\right)\left(\mathrm{SeO}_{3}\right)_{4}$ PBU lie parallel to the $c$-axis (Figure $4 \mathrm{a}$, top), resulting in the lone pairs of the $\left[\mathrm{SeO}_{3}\right]^{2-}$ groups being perfectly parallelaligned, highly favorable for the formation of an NCS structure. Compound 2 features a 3D honeycomb-like framework containing a tunnel with the diameter of about $9.88 \AA$. The structure analysis above demonstrates that $\left[\mathrm{SeO}_{3}\right]^{2-}$ anions, the secondary functional anions, and the flexibility of the rareearth-metal-based polyhedra all play key roles in determining the framework structures and the macroscopic centricities of crystals 1-3 (1 NCS, 2 polar, and $3 \mathrm{CS}$ ). In particular, monodentate $\mathrm{F}^{-}$anions and tight-binding trinuclear $\mathrm{Lu}_{3}\left(\mu_{3}-\mathrm{F}\right)$ metal polyhedra may favor enhancement in the structure polarity and accordingly the NLO performance of 2 .

To better understand the great difference in SHG effects between 1 and 2, local dipole moment calculations on $\mathrm{SeO}_{3}$ polyhedra have been performed (Table S8) by utilizing a reported method. ${ }^{68}$ The lone electron pair is given a charge of -2 and is localized $1.22 \AA$ from the $\mathrm{Se}^{4+}$ cation for the lone electron pair-containing unit. ${ }^{69}$ For $\mathbf{1}$, the calculated dipole moments for the $\mathrm{SeO}_{3}$ polyhedra are 0.507-10.24 D. However, the $x$-, $y$ - and $z$-components of the polarizations from the $\mathrm{Se}(1) \mathrm{O}_{3}$ and $\mathrm{Se}(2) \mathrm{O}_{3}$ polyhedra cancel completely, which is consistent with the weak SHG signal observed for 1. As 2 crystallizes in the space group $P 6_{3}$, the $x$ - and $y$-components of the polarizations from the $\left[\mathrm{SeO}_{3}\right]^{2-}$ groups within a unit cell cancel completely, while the $z$-component adds to give a value of $-12.496 \mathrm{D}$, which is in good agreement with the previously reported values. ${ }^{53}$ The polarizations constructively add to produce a large macroscopic polarization along the polar axis, resulting in the large observed $\mathrm{SHG}$ response of ca. $2.5 \times \mathrm{KDP}$ for 2 .

Theoretical Calculations. To gain further insight into the electronic structures, theoretical calculations on the com- pounds 1 and 2 were performed using DFT. The band structures show that $\mathbf{1}$ and $\mathbf{2}$ are indirect band gap compounds (Figure S10) because the valence band maximum (VBM) and the conduction band minimum $(\mathrm{CBM})$ are at different points $(\mathrm{G}$ and $\mathrm{X}$ for $\mathbf{1}$ and $\mathrm{M}$ and $\mathrm{G}$ for $\mathbf{2}$ ). The calculated band gaps were $4.70 \mathrm{eV}$ for $\mathbf{1}$ and $4.89 \mathrm{eV}$ for $\mathbf{2}$, and these values are larger than the experimental band gaps, which may be attributed to the strong excitonic effects as well as different binding energies of excitons in $\mathbf{1}$ and $2^{70}$ To better understand the VBM and CBM of $\mathbf{1}$ and $\mathbf{2}$, the electron densities of the VBMs and CBMs are given in Figure S11. The VBM of $\mathbf{1}$ consists of O $2 p$ states and Se $4 p$ states, while the CBM is delocalized and largely composed of states from the $\left[\mathrm{SeO}_{3}\right]^{2-}$ groups. As for 2, the VBM consists mainly of $2 p$ states from the $\mathrm{O}$ atoms together with a few states of the Se atoms, significantly different from the VBM of $\mathbf{1}$. The CBM of $\mathbf{2}$ is similar to that of $\mathbf{1}$. The charge-transfer from the CBM to the VBM in $\mathbf{2}$ is larger than that of $\mathbf{1}$, or in other words, the electronic polarization in $\mathbf{2}$ is larger than that of $\mathbf{1}$. Because the electronic polarizability has a significant influence on the nonlinear responses of materials, the DFT calculations are consistent with 2 showing a larger SHG efficiency than 1, which is borne out by the SHG measurements. The optical behaviors are closely related to the electron transitions from valence bands (VBs) to conduction bands (CBs), so we have therefore examined the density of states (DOS) to identify the characteristics of the electronic states. As shown in Figure 7, the VB edges below the Fermi levels predominantly originate from $\mathrm{O} 2 \mathrm{p}$ states, while the bottoms of the CBs consist mainly of $\mathrm{Lu}^{3+}, \mathrm{O} 2 \mathrm{p}$ and $\mathrm{Se} 4 \mathrm{p}$ orbitals. Hybridization of the cations and the $\left[\mathrm{SeO}_{3}\right]^{2-}$ anions should therefore be responsible for the band gaps and optical properties of $\mathbf{1}$ and $\mathbf{2}$.

In view of Kleinman's symmetry restriction, there are three independent SHG tensors for $\mathbf{1}$ and four independent SHG tensors for 2 . The SHG coefficients of $d_{14}, d_{25}$, and $d_{36}$ for 1 at $1064 \mathrm{~nm}(1.165 \mathrm{eV})$ are $1.05 \times 10^{-9}, 0.76 \times 10^{-9}$, and $1.88 \times 10^{-9} \mathrm{esu}$, respectively (Figure S12a), while the SHG tensors $d_{14}, d_{15}, d_{31}$, and $d_{33}$ for 2 were calculated to be $4.18 \times$ $10^{-9}, 1.87 \times 10^{-9}, 2.38 \times 10^{-9}$, and $5.77 \times 10^{-9} \mathrm{esu}$, respectively (Figure S12b). The mean SHG tensors of the two compounds were estimated to be 1.0 and 2.9 times that of KDP. These
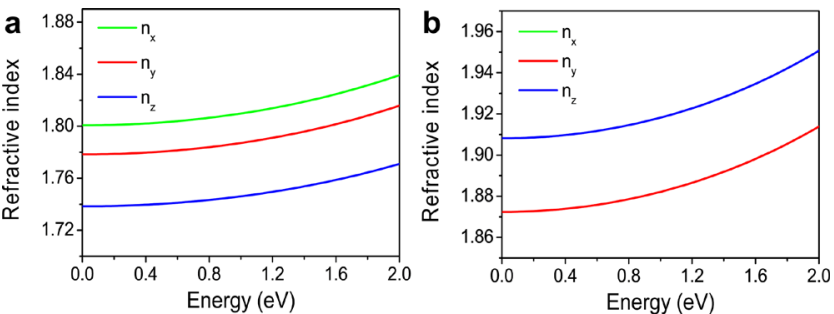

Figure 8. Calculated frequency-dependent refractive indices of 1 (a) and 2 (b).

values are slightly different from the experimental values $(0.1$ $\times$ KDP for 1 and $2.5 \times$ KDP for 2 ), which may be attributed to the fact that the SHG calculations are based on single-crystal structures that may generate larger SHG effects. The dispersion curves of refractive indices calculated according to the formula $n^{2}(\omega)=\varepsilon(\omega)$ display strong anisotropy: $n_{x}>n_{y}>n_{z}$ for 1 and $n_{x}=n_{y}<n_{z}$ for 2 (Figure 8). The $n_{x}, n_{y}$, and $n_{z}$ values for 1 at $1064 \mathrm{~nm}(1.165 \mathrm{eV})$ are calculated to be $1.813,1.790$, and 1.748 , respectively, while those for 2 are computed to be $1.922,1.922$ and 1.886, respectively. The calculated birefrin- 
gencies at $1064 \mathrm{~nm}$ are 0.065 and 0.036 for 1 and 2, respectively, favorable for SHG phase-matchability.

\section{CONCLUSIONS}

In summary, we have synthesized NCS 1 by a hydrothermal reaction and successfully transformed the NCS 1 into polar $\mathbf{2}$ and CS 3 (as a comparison) by applying the APS strategy. 2 features a 3D framework structure and is the first example of a fluorinated lutetium selenite. In contrast to $\mathbf{1}$, which shows a very weak NLO response, and $\mathbf{3}$, which displays no SHG response, 2 exhibits a strong SHG response (2.5 times that of KDP), which is the highest value among all rare-earthmetal-based NLO selenites. 2 additionally possesses a wide band gap $(3.57 \mathrm{eV})$ and optical transparency window $(0.35-10.3 \mu \mathrm{m})$, a large laser damage threshold $(36 \times \mathrm{Ag}-$ $\left.\mathrm{GaS}_{2}\right)$, and high thermal stability $\left(\sim 550{ }^{\circ} \mathrm{C}\right)$. These observations indicate that $\mathbf{2}$ is a potential NLO crystalline material in the near-ultraviolet to mid-IR region. Theoretical calculations further confirm that the enhanced SHG response in $\mathbf{2}$ originates from the $\left[\mathrm{SeO}_{3}\right]^{2-}$ anions and the inherent variability of rare-earth-metal-based polyhedra. The different coordination geometries, distinct centricities, and differing NLO performance of these rare-earth lutetium-based selenites can be attributed to the different denticities of the secondary functional anions. The discovery of rare-earth lutetium-based selenites with twofold-anions may enrich the family of selenites as NLO materials. The structure-manipulation achieved via the APS approach, modulating the macroscopic centricities and thereby the NLO performance of these rare-earth-metal-based selenite materials, provides insight into the future design and synthesis of novel NCS NLO materials.

\section{ASSOCIATED CONTENT}

\section{Supporting Information}

Selected bond distances and angles, hydrogen-bonding interactions, summary of rare-earth-based NLO selenites, dipole moment calculations, XRD, additional structures, IR, UV-Vis-NIR, TG, and theoretical calculations (PDF).

X-ray crystallographic data (CIF).

This material is available free of charge via the Internet at http://pubs.acs.org.

\section{AUTHOR INFORMATION}

\section{Corresponding Author}

*E-mail: chizhang@tongji.edu.cn

Phone: (+86)21-65988860.

\section{ORCID}

Chao Wu: 0000-0002-8016-0359

Longhua Li: 0000-0003-1817-5039

Zhipeng Huang: 0000-0002-7113-2903

Mark G. Humphrey: 0000-0002-4433-6783

Chi Zhang: 0000-0002-5237-8916

\section{Notes}

The authors declare no competing financial interest.

\section{ACKNOWLEDGMENT}

This research was financially supported by the National Natural Science Foundation of China (nos. 51432006 and 51172100), the Ministry of Education of China for the
Changjiang Innovation Research Team (no. IRT13R24), the Ministry of Education and the State Administration of Foreign Experts Affairs for the 111 Project (no. B13025), and the National and Shanghai Postdoctoral Program for Innovative Talents (nos. BX201800216 and 2018192). M. G. H. and C. Z. thank the Australian Research Council for support (DP170100411). The authors thank G. Z. and B. X. L. at FJIRSM for help with the LDT measurements.

\section{REFERENCES}

(1) Shi, G.; Wang, Y.; Zhang, F.; Zhang, B.; Yang, Z.; Hou, X.; Pan, S.; Poeppelmeier, K. R. Finding the next deepultraviolet nonlinear optical material: $\mathrm{NH}_{4} \mathrm{~B}_{4} \mathrm{O}_{6} \mathrm{~F}$. J. Am. Chem. Soc. 2017, 139, 10645-10648.

(2) Yu, H. W.; Nisbet, M. L.; Poeppelmeier, K. R. Assisting the effective design of polar iodates with early transition-metal oxide fluoride anions. J. Am. Chem. Soc. 2018, 140, 88688876.

(3) Lin, D. H.; Luo, M.; Lin, C. S.; Xu, F.; Ye, N. $\mathrm{KLi}\left(\mathrm{HC}_{3} \mathrm{~N}_{3} \mathrm{O}_{3}\right) \cdot 2 \mathrm{H}_{2} \mathrm{O}$ : solvent-drop grinding method toward the hydro-isocyanurate nonlinear optical crystal. J. Am. Chem. Soc. 2019, 141, 3390-3394.

(4) Yu, H. W.; Koocher, N. Z. Rondinelli, J. M.; Halasyamani, P. $\mathrm{S} . \mathrm{Pb}_{2} \mathrm{BO}_{3} \mathrm{I}$ : a borate iodide with the largest second-harmonic generation (SHG) response in the $\mathrm{KBe}_{2} \mathrm{BO}_{3} \mathrm{~F}_{2}$ (KBBF) family of nonlinear optical (NLO) materials. Angew. Chem. Int. Ed. 2018, 57, 6100-6103.

(5) Wu, C.; Yang, G.; Humphrey, M. G.; Zhang, C. Recent advances in ultraviolet and deep-ultraviolet second-order nonlinear optical crystals. Coord. Chem. Rev. 2018, 375, 459488.

(6) Becker, P. Borate materials in nonlinear optics. Adv. Mater. 1998, 10, 979-992.

(7) Chao, T. L.; Chang, W. J.; Wen, S. H.; Lin, Y. Q.; Chang, B. C.; Lii, K. H. Titanosilicates with Strong Phase-matched second harmonic generation responses. J. Am. Chem. Soc. 2016, 138, 9061-9064.

(8) Mutailipu, M.; Pan, S. L. Emergent deep-ultraviolet nonlinear optical candidates. Angew. Chem. Int. Ed., 2020, DOI: 10.1002/anie.201913974.

(9) Mei, L. F.; Wang, Y. B.; Chen, C. T.; Wu, B. C. Nonlinear optical materials based on $\mathrm{MBe}_{2} \mathrm{BO}_{3} \mathrm{~F}_{2}(\mathrm{M}=\mathrm{Na}, \mathrm{K})$. J. Appl. Phys. 1993, 74, 7014-7015.

(10) Chen, C. T.; Wu, B. C.; Jiang, A. D.; You, G. M. A new-type ultraviolet SHG crystal $\beta-\mathrm{BaB}_{2} \mathrm{O}_{4}$. Sci. Sin., Ser. B 1985, 28 , 235-243.

(11) Chen, C. T.; Wu, Y. C.; Jiang, A. D.; Wu, B. C.; You, G. M.; Li, R. K.; Lin, S. J. New nonlinear-optical crystal: $\mathrm{LiB}_{3} \mathrm{O}_{5} . J$. Opt. Soc. Am. B 1989, 6, 616-621.

(12) De Yoreo, J. J.; Burnham, A. K.; Whitman, P. K. Developing $\mathrm{KH}_{2} \mathrm{PO}_{4}$ and $\mathrm{KD}_{2} \mathrm{PO}_{4}$ crystals for the world's most power laser. Int. Mater. Rev. 2002, 47, 113-152.

(13) Bierlein, J. D.; Vanherzeele, H. Potassium titanyl phosphate: properties and new applications. J. Opt. Soc. Am. B 1989, 6, 622-633.

(14) Tell, B.; Kasper, H. M. Optical and electrical properties of $\mathrm{AgGaS}_{2}$ and $\mathrm{AgGaSe}_{2}$. Phys. Rev. B 1971, 4, 4455-4459.

(15) Ok, K. M. Toward the rational design of novel noncentrosymmetric materials: factors influencing the framework structures. Acc. Chem. Res. 2016, 49, 2774-2785.

(16) Lan, H. C.; Liang, F.; Jiang, X. X.; Zhang, C.; Yu, H. H.; Lin, Z. S.; Zhang, H. J.; Wang, J. Y.; Wu, Y. C. Pushing nonlinear optical oxides into the mid-infrared spectral region beyond $10 \mu \mathrm{m}$ : Design, synthesis, and characterization of $\mathrm{La}_{3} \mathrm{SnGa}_{5} \mathrm{O}_{14}$. J. Am. Chem. Soc. 2018, 140, 4684-4690. 
(17) Zhang, M.; Hu, C.; Abudouwufu, T.; Yang, Z. H.; Pan, S. L. Functional materials design via structural regulation originated from ions introduction: a study case in cesium iodate system. Chem. Mater. 2018, 30, 1136-1145.

(18) Lu, J.; Yue, J. N.; Xiong, L.; Zhang, W. K.; Chen, L.; Wu, L. M. Uniform alignment of non- $\pi$-conjugated species enhances deep ultraviolet optical nonlinearity. J. Am. Chem. Soc. 2019, 141, 8093-8097.

(19) Li, C.; Yin, W. L.; Gong, P. F.; Li, X. S.; Zhou, M. L.; Mar, A.; Lin, Z. S.; Yao, J. Y.; Wu, Y. C.; Chen, C. T. Trigonal planar $\left[\mathrm{HgSe}_{3}\right]^{4-}$ Unit: a new kind of basic functional group in IR nonlinear optical materials with large susceptibility and physicochemical stability. J. Am. Chem. Soc. 2016, 138, 6135-6138.

(20) Lu, W. Q.; Gao, Z. L.; Liu, X. T.; Tian, X. X.; Wu, Q.; Li, C. G.; Sun, Y. X.; Liu, Y.; Tao, X. T. Rational design of a $\mathrm{LiNbO}_{3}$-like nonlinear optical crystal, $\mathrm{Li}_{2} \mathrm{ZrTeO}_{6}$, with high laser-damage threshold and wide mid-IR transparency window. J. Am. Chem. Soc. 2018, 140, 13089-13096.

(21) Mutailipu, M.; Zhang, M.; Zhang, B. B.; Wang, L. Y.; Yang, Z. H.; Zhou, X.; Pan, S. L. $\mathrm{SrB}_{5} \mathrm{O}_{7} \mathrm{~F}_{3}$ functionalized with $\left[\mathrm{B}_{5} \mathrm{O}_{9} \mathrm{~F}_{3}\right]^{6-}$ chromophores: accelerating the rational design of deep-ultraviolet nonlinear optical materials. Angew. Chem. Int. Ed., 2018, 57, 6095-6099.

(22) Wu, C.; Lin, L.; Jiang X. X.; Lin, Z. S.; Huang, Z. P.; Humphrey, M. G.; Halasyamani, P. S.; Zhang, C. $\mathrm{K}_{5}\left(\mathrm{~W}_{3} \mathrm{O}_{9} \mathrm{~F}_{4}\right)\left(\mathrm{IO}_{3}\right)$ : an efficient mid-infrared nonlinear optical compound with high laser damage threshold. Chem. Mater. 2019, 31, 10100-10108.

(23) Chang, H. Y.; Kim, S. W.; Halasyamani, P. S. Polar hexagonal tungsten oxide (HTO) materials: (1) synthesis, characterization, functional properties, and structure-property relationships in $\mathrm{A}_{2}\left(\mathrm{MoO}_{3}\right)_{3}\left(\mathrm{SeO}_{3}\right)\left(\mathrm{A}=\mathrm{Rb}^{+}\right.$and $\left.\mathrm{Tl}^{+}\right)$and (2) classification, structural distortions, and second-harmonic generating properties of known polar HTOs. Chem. Mater. 2010, 22, 3241-3250.

(24) Cao, X. L.; Hu, C. L.; Kong, F.; Mao, J. G. $\mathrm{Cs}\left(\mathrm{TaO}_{2}\right)_{3}\left(\mathrm{SeO}_{3}\right)_{2}$ and $\mathrm{Cs}(\mathrm{TiOF})_{3}\left(\mathrm{SeO}_{3}\right)_{2}$ : structural and second harmonic generation changes induced by the different $\mathrm{d}^{0}$-TM coordination octahedra. Inorg. Chem. 2015, 54, 38753882 .

(25) Sivakumar, T.; Chang, H. Y.; Baek, J.; Halasyamani, P. S. Two new noncentrosymmetric polar oxides: synthesis, characterization, second-harmonic generating, and pyroelectric measurements on $\mathrm{TlSeVO}_{5}$ and $\mathrm{TlTeVO}_{5}$. Chem. Mater. 2007, 19, 4710-4715.

(26) Chang, H. Y.; Kim, S. H.; Ok, K. M.; Halasyamani, P. S. New polar oxides: synthesis, characterization, calculations, and structure-property relationships in $\mathrm{RbSe}_{2} \mathrm{~V}_{3} \mathrm{O}_{12}$ and $\mathrm{TlSe}_{2} \mathrm{~V}_{3} \mathrm{O}_{12}$. Chem. Mater. 2009, 21, 1654-1662.

(27) Cao, X. L.; Hu, C. L.; Kong, F.; Mao J. G. Explorations of new SHG materials in the alkali-metal- $\mathrm{Nb}^{5+}$-selenite system. Inorg. Chem. 2015, 54, 10978-10984.

(28) Nguyen S. D.; Halasyamani, P. S. Synthesis, structure, and characterization of two new polar sodium tungsten selenites: $\mathrm{Na}_{2}\left(\mathrm{WO}_{3}\right)_{3}\left(\mathrm{SeO}_{3}\right) \cdot 2 \mathrm{H}_{2} \mathrm{O}$ and $\mathrm{Na}_{6}\left(\mathrm{~W}_{6} \mathrm{O}_{19}\right)\left(\mathrm{SeO}_{3}\right)_{2}$. Inorg. Chem. 2013, 52, 2637-2647.

(29) Lee, D. W.; Oh, S. J.; Halasyamani, P. S.; Ok, K. M. New quaternary tellurite and selenite: synthesis, structure, and characterization of centrosymmetric $\mathrm{InVTe}_{2} \mathrm{O}_{8}$ and noncentrosymmetric InVSe 2 O8. Inorg. Chem. 2011, 50, 4473-4480.

(30) Liang, M. L.; Hu, C. L.; Kong, F.; Mao, J. G. BiFSeO 3 : An excellent SHG material designed by aliovalent substitution. $J$. Am. Chem. Soc. 2016, 138, 9433-9436.

(31) You, F. G.; Liang, F.; Huang, Q.; Hu, Z. G.; Wu, Y. C.; Lin, Z. S. $\mathrm{Pb}_{2} \mathrm{GaF}_{2}\left(\mathrm{SeO}_{3}\right)_{2} \mathrm{Cl}$ : band engineering strategy by aliovalent substitution for enlarging bandgap while keeping strong second harmonic generation response. J. Am. Chem. Soc. 2019, 138, 748-752.

(32) Kim, S. H.; Yeon, J.; Halasyamani, P. S. Noncentrosymmetric polar oxide material, $\mathrm{Pb}_{3} \mathrm{SeO}_{5}$ : synthesis, characterization, electronic structure calculations, and structure-property relationships. Chem. Mater. 2009, 21, 5335-5342.

(33) Wang, X. X.; Jiang, X. X.; Liu, H. M.; Yang, L.; Lin, Z. S.; Hu, Z. G.; Meng, X. G.; Chen, X. G.; Qin, J. G. $\mathrm{Pb}_{3}\left(\mathrm{SeO}_{3}\right) \mathrm{Br}_{4}$ : a new nonlinear optical material with enhanced SHG response designed via an ion-substitution strategy. Dalton Trans. 2018, 47, 1911-1917.

(34) Geng, L.; Li, Q.; Meng, C. Y.; Dai, K.; Lu, H. Y.; Lin, C. S.; Cheng, W. D. $\mathrm{BaBi}\left(\mathrm{SeO}_{3}\right)_{2} \mathrm{Cl}$ : a new polar material showing high second-harmonic generation efficiency enhanced by constructive alignment of chloride ions. J. Mater. Chem. C. 2015, 3, 12290-12296.

(35) Gong, Y. P.; Hu, C. L.; Ma, Y. X.; Mao, J. G.; Kong, F. $\mathrm{Pb}_{2} \mathrm{Cd}\left(\mathrm{SeO}_{3}\right)_{2} \mathrm{X}_{2}(\mathrm{X}=\mathrm{Cl}$ and $\mathrm{Br})$ : two halogenated selenites with phase matchable second harmonic generation. Inorg. Chem. Front. 2019, 6, 3133-3139.

(36) Ma, Y. X.; Hu, C. L.; Li, B. X.; Kong, F.; Mao, J. G. $\mathrm{PbCdF}\left(\mathrm{SeO}_{3}\right)\left(\mathrm{NO}_{3}\right)$ : a nonlinear optical material produced by synergistic effect of four functional units, Inorg. Chem. 2018, 57, 11839-11846.

(37) Halasyamani, P. S. Asymmetric cation coordination in oxide materials: influence of lone-pair cations on the intraoctahedral distortion in $\mathrm{d}^{0}$ transition metals. Chem. Mater. 2004, 16, 3586-3592.

(38) Cao, L.; Song, Y. X.; Peng, G.; Luo, M.; Yang, Y.; Lin, C. S.; Zhao, D.; Xu, F.; Lin, Z. S.; Ye, N. Refractive index modulates second-harmonic responses in $\mathrm{RE}_{8} \mathrm{O}\left(\mathrm{CO}_{3}\right)_{3}(\mathrm{OH})_{15} \mathrm{X}$ $(\mathrm{RE}=\mathrm{Y}, \mathrm{Lu} ; \mathrm{X}=\mathrm{Cl}, \mathrm{Br})$ : rare-earth halide carbonates as ultraviolet nonlinear optical materials. Chem. Mater. 2019, 31, 2130-2137.

(39) Zhao, H. J.; Zhang, Y. F.; Chen, L. Strong kleinmanforbidden second harmonic generation in chiral sulfide: $\mathrm{La}_{4} \mathrm{InSbS}_{9 .} . J$. Am. Chem. Soc. 2012, 134, 1993-1995.

(40) Song, S. Y.; Ok, K. M. $\mathrm{LiSc}\left(\mathrm{SeO}_{3}\right)_{2} \cdot \mathrm{xH}_{2} \mathrm{O}(0 \leq \mathrm{x} \leq 1)$ : new selenites revealing water molecule-driven extremely high temperature single-crystal-to-single-crystal transformations. Cryst. Growth Des. 2016, 16, 3076-3080.

(41) Zhang, S. Y.; Mao, J. G. Syntheses, crystal structures, magnetic and luminescent properties of two classes of molybdenum(VI) rich quaternary lanthanide selenites. Inorg. Chem 2011, 56, 4934-4943.

(42) Eaton, T. M.; Groom, R. A.; Silver, M. A.; Albrecht-Schmitt, T. E. Diverse lanthanide coordination and selective ion exchange in the microporous selenites $\mathrm{Na}_{4} \mathrm{Ln}_{4}\left(\mathrm{SeO}_{3}\right)_{7} \mathrm{O} \cdot \mathrm{nH}_{2} \mathrm{O}$ $(\mathrm{Ln}=\mathrm{Gd}, \mathrm{Tb}, \mathrm{Dy}, \mathrm{Ho}, \mathrm{Er}, \mathrm{Tm}$, and Yb), Cryst. Growth Des. 2016, 16, 1453-1457.

(43) Pan, Y.; Guo, S. P.; Liu, B. W.; Xue, H. G.; Guo, G. C. Second order nonlinear optical crystals with mixed anions. Coord. Chem. Rev. 2018, 374, 464-496.

(44) Mao, F. F.; Hu, C. L.; Li, B. X.; Mao, J. G. Acentric $\mathrm{La}_{3}\left(\mathrm{IO}_{3}\right)_{8}(\mathrm{OH})$ and $\mathrm{La}\left(\mathrm{IO}_{3}\right)_{2}\left(\mathrm{NO}_{3}\right)$ : partial substitution of iodate anions in $\mathrm{La}\left(\mathrm{IO}_{3}\right)_{3}$ by hydroxide or nitrate anion. Inorg. Chem. 2017, 56, 14357-14365.

(45) Lin, J.; Diefenbach, K.; Silver, M. A.; Dalal, N. S.; AlbrechtSchmitt, T. E. Structure-property correlations in the heterobimetallic $4 \mathrm{f} / 3 \mathrm{~d}$ materials $\mathrm{Ln}_{2} \mathrm{M}\left(\mathrm{TeO}_{3}\right)_{2}\left(\mathrm{SO}_{4}\right)(\mathrm{Ln}=\mathrm{Y}, \mathrm{Nd}$, $\mathrm{Sm}, \mathrm{Eu}, \mathrm{Gd}, \mathrm{Tb}, \mathrm{Dy}, \mathrm{Ho}, \mathrm{Er}, \mathrm{Tm}, \mathrm{Yb}$, or $\mathrm{Lu} ; \mathrm{M}=\mathrm{Co}$ or $\mathrm{Zn})$. Cryst. Growth Des. 2015, 15, 4606-4615.

(46) Sheldrick, G. M. SHELXS-97: Program for the Solution of Crystal Structures, University of Göttingen, Germany, 1997.

(47) Sheldrick, G. M. SHELXL-97: Program for the Refinement of Crystal Structures, University of Göttingen, Germany, 1997. 
(48) Spek, A. L. Single-crystal structure validation with the program PLATON. J. Appl. Crystallogr. 2003, 36, 7-13.

(49) Wendlandt, W. M.; Hecht, H. G. Reflectance Spectroscopy, Interscience: New York, 1966.

(50) Kurtz, S. K.; Perry, T. T. A powder technique for the evaluation of nonlinear optical materials. J. Appl. Phys. 1968, 39, 3798-3813.

(51) Zhang, M. J.; Jiang, X. M.; Zhou, L. J.; Guo, G. C. Two phases of $\mathrm{Ga}_{2} \mathrm{~S}_{3}$ : promising infrared second-order nonlinear optical materials with very high laser induced damage thresholds. J. Mater. Chem. C 2013, 1, 4754-4760.

(52) Kresse, G.; Furthmuller, J. Efficient iterative schemes for ab initio total-energy calculations using a plane-wave basis set. Phys. Rev. B 1996, 54, 11169-11186.

(53) Perdew, J. P.; Burke, K.; Ernzerhof, M. Generalized gradient approximation made simple. Phys. Rev. Lett. 1996, 77, 38653868.

(54) Blochl, P. E. Projector augmented-wave method. Phys. Rev. $B$ 1994, 50, 17953-17979.

(55) Kresse, G.; Joubert, D. From ultrasoft pseudopotentials to the projector augmented-wave method. Phys. Rev. B 1999, 59, $1758-1775$

(56) Sharma, S.; Ambrosch-Draxl, C. Linear and second-order optical response from first principles. arXiv:condmat/0305016v2.

(57) Wu, Q.; Liu, H. M.; Kang, L.; Lin, Z. S.; Meng, X. G.; Chen, X. G.; Qin, J. G. $\mathrm{Rb}_{2} \mathrm{SeOCl}_{4} \cdot \mathrm{H}_{2} \mathrm{O}$ : a polar material among the alkali metal selenite halides with a strong SHG response. Dalton Trans. 2016, 45, 17723-17728.

(58) Lee, E. P.; Song, S. Y.; Lee, D. W.; Ok, K. M. New bismuth selenium oxides: syntheses, structures, and characterizations of centrosymmetric $\mathrm{Bi}_{2}\left(\mathrm{SeO}_{3}\right)_{2}\left(\mathrm{SeO}_{4}\right)$ and $\mathrm{Bi}_{2}\left(\mathrm{TeO}_{3}\right)_{2}\left(\mathrm{SeO}_{4}\right)$ and noncentrosymmetric $\mathrm{Bi}\left(\mathrm{SeO}_{3}\right)\left(\mathrm{HSeO}_{3}\right)$. Inorg. Chem. 2013, 52, 4097-4103.

(59) de Pedro, M.; Enjalbert, R.; Castro, A.; Trombe, J. C.; Galy, J. Synthesis, characterization, and crystal structure of $\mathrm{Nd}\left(\mathrm{HSeO}_{3}\right)\left(\mathrm{SeO}_{3}\right) \cdot 2 \mathrm{H}_{2} \mathrm{O}$. J. Solid State Chem. 1994, 108, 87-93.

(60) Harrison, W. T. A. $\left[\mathrm{Y}\left(\mathrm{HSeO}_{3}\right)\left(\mathrm{SeO}_{3}\right)\left(\mathrm{H}_{2} \mathrm{O}\right)\right] \cdot \mathrm{H}_{2} \mathrm{O}$. Acta Crystallogr. E 2006, 62, i52-i54.

(61) Koskenlinna, M.; Mutikainen, I.; Leskelae, M.; Niinisto, L. $\mathrm{Sm}\left(\mathrm{HSeO}_{3}\right)\left(\mathrm{SeO}_{3}\right)\left(\mathrm{H}_{2} \mathrm{O}\right) \cdot \mathrm{H}_{2} \mathrm{O}$. Acta Crystallogr. C 1994, C50, 1384-1386.

(62) Brese, N. E.; O'Keeffe, M. Bond-valence parameters for solids. Acta Crystallogr. 1991, B47, 192-197.

(63) Wickleder, M. S.; Krügermann, I. $\mathrm{Gd}_{3}\left(\mathrm{SeO}_{3}\right)_{4} \mathrm{~F}$ : a fluoride selenite with $\mu_{3}-\mathrm{SeO}_{3}{ }^{2-}$ and $\mu_{3}-\mathrm{F}^{-}$capped $\mathrm{Gd}_{3}$-rings, $Z$. Anorg. Allg. Chem. 2000, 626, 1725-1727.

(64) Krügermann, I.; Wickleder, M. S. Syntheses and crystal structures of $\mathrm{Er}_{2}\left(\mathrm{SeO}_{3}\right)_{3}$ and $\mathrm{Dy}_{3}\left(\mathrm{SeO}_{3}\right)_{4} \mathrm{~F}$, J. Solid State Chem. 2002, 167, 113-118.

(65) Lipp, C.; Schleid, T. $\mathrm{HoF}\left[\mathrm{SeO}_{3}\right]$ and $\mathrm{Ho}_{3} \mathrm{~F}\left[\mathrm{SeO}_{3}\right]_{4}$ : two fluoride-derivatized holmium (oxo)selenates(IV), Z. Anorg. Allg. Chem. 2008, 634, 1662-1668.

(66) Zhang, J. H.; Wang, Q. B.; Chen, C. L.; Luo, J. X.; Hu, C. L.; Song, J. L.; Mao, J. G. RbSe ${ }_{3} \mathrm{~B}_{2} \mathrm{O}_{9}(\mathrm{OH})$ and $\mathrm{CsSe}_{3} \mathrm{~B}_{2} \mathrm{O}_{9}(\mathrm{OH})$ : one dimensional boroselenite-based anionic frameworks with second harmonic generation properties. Dalton Trans. 2018, 47, 5764-5770.

(67) Meng, C. Y.; Geng, L.; Chen, W. T.; Wei, M. F.; Dai, K.; Lu, H. Y.; Cheng, W. D. Syntheses, structures, and characterizations of a new second-order nonlinear optical material: $\mathrm{Pb}_{2}\left(\mathrm{SeO}_{3}\right)\left(\mathrm{NO}_{3}\right)_{2}$. J. Alloys Compd. 2015, 640, 39-44.

(68) Maggard, P. A.; Nault, T. S.; Stern, C. L.; Poeppelmeier, K. R. Alignment of acentric $\mathrm{MoO}_{3} \mathrm{~F}_{3}{ }^{3-}$ anions in a polar material: $\left(\mathrm{Ag}_{3} \mathrm{MoO}_{3} \mathrm{~F}_{3}\right)\left(\mathrm{Ag}_{3} \mathrm{MoO}_{4}\right) \mathrm{Cl}$. J. Solid State Chem. 2003, $175,27-33$.
(69) Galy, J.; Meunier, G.; Andersson, S.; Astrom, A. Stereochemical behavior of elements possessing nonbonded pairs. Germanium(II), arsenic(III), selenium(IV), bromine(V), tin(II), antimony(III), tellurium(IV), iodine(V), xenon(VI), thallium(I), lead(II), and bismuth(III) (oxides, fluorides, and oxyfluorides). J. Solid State Chem. 1975, 13, 142-159.

(70) Li, L. H.; Kontsevoi, O. Y.; Freeman, A. J. Electronic and optical excitations of the PTB7 crystal: First-principles GWBSE calculations. Phys. Rev. B: Condens. Matter Mater. Phys. 2014, 90, 195203. 
Table of Contents

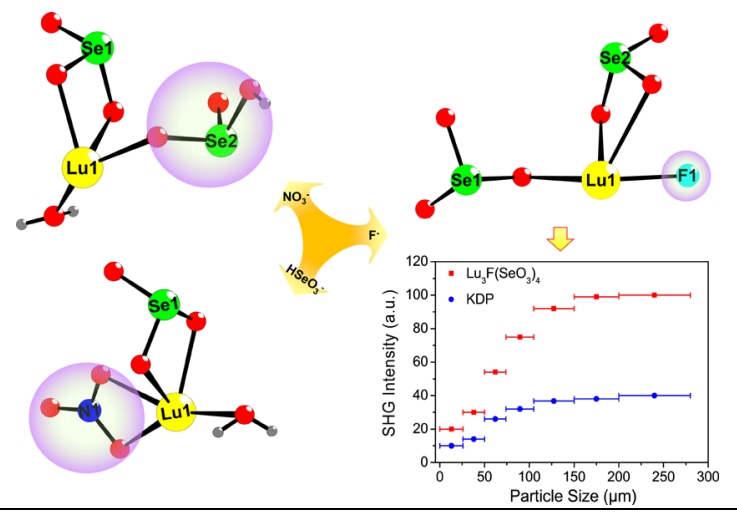

